\title{
The East Madagascar Current: Volume Transport and Variability Based on Long-Term Observations*
}

\author{
LEANDro Ponsoni, BorJa Aguiar-GonZÁlez, AND HERman RidderinkHOF \\ Royal Netherlands Institute for Sea Research (NIOZ), Den Burg, Texel, Netherlands \\ LEO R. M. MAAS \\ Royal Netherlands Institute for Sea Research (NIOZ), Den Burg, Texel, and Institute for Marine and \\ Atmospheric Research, Utrecht University, Utrecht, Netherlands
}

(Manuscript received 12 August 2015, in final form 25 December 2015)

\begin{abstract}
This study provides a long-term description of the poleward East Madagascar Current (EMC) in terms of its observed velocities, estimated volume transport, and variability based on both $\sim 2.5 \mathrm{yr}$ of continuous in situ measurements and $\sim 21 \mathrm{yr}$ of satellite altimeter data. An array of five moorings was deployed at $23^{\circ} \mathrm{S}$ off eastern Madagascar as part of the Indian-Atlantic Exchange in present and past climate (INATEX) observational program. On average, the EMC has a horizontal scale of about $60-100 \mathrm{~km}$ and is found from the surface to about 1000-m depth. Its time-averaged core is positioned at the surface, at approximately $20 \mathrm{~km}$ from the coast, with velocity of $79( \pm 21) \mathrm{cm} \mathrm{s}^{-1}$. The EMC mean volume transport is estimated to be $18.3( \pm 8.4)$ Sverdrups $\left(\mathrm{Sv} ; 1 \mathrm{~Sv} \equiv 10^{6} \mathrm{~m}^{3} \mathrm{~s}^{-1}\right.$ ). During the strongest events, maximum velocities and transport reach up to $170 \mathrm{~cm} \mathrm{~s}^{-1}$ and $50 \mathrm{~Sv}$, respectively. A good agreement is found between the in situ transport estimated over the first $8 \mathrm{~m}$ of water column $[0.32( \pm 0.13) \mathrm{Sv}]$ with the altimetry-derived volume transport $[0.28( \pm 0.09) \mathrm{Sv}]$. Results from wavelet analysis display a dominant nearly bimonthly (45-85 days) frequency band of transport variability, which explains about $41 \%$ of the transport variance. Altimeter data suggest that this band of variability is induced by the arrival of westward-propagating sea level anomalies, which in turn are likely represented by mesoscale cyclonic and anticyclonic eddies. Annual averages of the altimeter-derived surface transport suggest that interannual variabilities also play a role in the EMC system.
\end{abstract}

\section{Introduction}

In the last decades, the ocean circulation in the southwest Indian Ocean (SWIO) has drawn increasing attention from the scientific community. The main reason lies in the fact that the SWIO is a key region for the global overturning circulation and therefore to the climate system due to the interocean exchange between Indian and Atlantic Oceans. There large amounts of relatively warm and salty water leak from the Indian

\footnotetext{
* Supplemental information related to this paper is available at the Journals Online website: http://dx.doi.org/10.1175/JPO-D-150154.s1.

Corresponding author address: Leandro Ponsoni, NIOZ Royal Netherlands Institute for Sea Research, P.O. Box 59, 1790 AB Den Burg, Texel, Netherlands. E-mail: lponsoni@nioz.nl
}

Ocean to the Atlantic through the rings released by the Agulhas Current (AC) during its retroflection off the southern tip of Africa (Olson and Evans 1986; Gordon et al. 1992; de Ruijter et al. 1999; Lutjeharms 2006; Beal et al. 2011).

In addition to its importance in the climate system, the geostrophic circulation in the SWIO composes one of the most intriguing western boundary current systems of all subtropical gyres. Unlike other western boundaries, the presence of Madagascar Island imposes a partitioning of the poleward flow into two components: one along the Mozambique Channel (MC) and another along the east Madagascar coast. In the MC the flow is dominated by southward-propagating anticyclonic eddies that fill almost the whole channel, both in depth and in width (de Ruijter et al. 2002; Ridderinkhof and de Ruijter 2003; Ridderinkhof et al. 2010; Ullgren et al. 2012). On the other hand, off east Madagascar, the poleward flow is organized as a typical western boundary current 
(Duncan 1970; Lutjeharms et al. 1981; Schott et al. 1988), the East Madagascar Current (EMC). We note here that the EMC is also referred to as the Southeast Madagascar Current in the literature (e.g., Schott et al. 2009).

The main aim of this paper is to provide a long-term description of the EMC in terms of its observed velocities, estimated volume transport, and variability, based on both $\sim 2.5 \mathrm{yr}$ of continuous in situ measurements and $\sim 21 \mathrm{yr}$ of satellite altimeter data.

The origin of the EMC is linked to the northern boundary of the South Indian Subtropical Gyre, represented by the South Equatorial Current (SEC). As the westward SEC approaches and crosses the Mascarene Plateau, near $60^{\circ} \mathrm{E}$, it splits into northern and southern cores. The former carries 25 Sverdrups $\left(\mathrm{Sv} ; 1 \mathrm{~Sv} \equiv 10^{6} \mathrm{~m}^{3} \mathrm{~s}^{-1}\right)$ between $10^{\circ}$ and $14^{\circ} \mathrm{S}$, whereas the latter transports about 20-25 Sv between $17^{\circ}$ and $20^{\circ} \mathrm{S}$ (New et al. 2007). Farther west, the southern SEC core bifurcates toward the east coast of Madagascar into two branches: the poleward EMC and the equatorward North Madagascar Current (NMC, also known as the Northeast Madagascar Current), which in turn joins the northern SEC core near the northern tip of the island (Schott et al. 1988; Swallow et al. 1988; Chapman et al. 2003; Siedler et al. 2006). According to Chen et al. (2014), the bifurcation of the southern SEC core, integrated over the upper thermocline depth, occurs on average at $18^{\circ} \mathrm{S}$, varying throughout a year by about $1^{\circ}$, with its northernmost and southernmost positions found in November-December and June-July, respectively.

Downstream, the EMC seems to break up into a series of nearly symmetric dipolar vortex pairs off the southern tip of Madagascar. De Ruijter et al. (2004) and Ridderinkhof et al. (2013) suggest that the detachment of strong dipolar structures leads to events of early (easternmost) AC retroflection. Other suggestions have been presented in the literature on how the EMC contributes with source waters to the $\mathrm{AC}$, such as by means of a retroflection regime characterized by castoff eddies and fragments feeding into the AC system (Lutjeharms et al. 1981), through a minimized contribution due to a complete EMC retroflection (Lutjeharms 1988) or in the form of a direct southwestward flow to the upstream Agulhas region (Gründlingh 1993).

Most of the previous transport estimates for the EMC have been computed through geostrophic calculations based on expendable bathythermograph (XBT) and conductivity-temperature-depth (CTD) vertical profiling. Therefore, a computation of the geostrophic velocity field and its associated transport (e.g., Fomin 1964) depends on the choice of a velocity reference level (and salinity estimates in the XBT case). Additionally, factors such as time variability, geographical location, and differences in the horizontal and vertical scales involved in the geostrophic calculations also contributed to the disparities in the EMC volume transport found in the literature: 20-24 Sv (Wyrtki 1971), $35 \mathrm{~Sv}$ (Harris 1972), $41 \mathrm{~Sv}$ (Lutjeharms et al. 1981), and $35 \mathrm{~Sv}$ (Stramma and Lutjeharms 1997). The reference level problem has been minimized by Swallow et al. (1988), who found 20.6 Sv of alongshore transport by using a reference level $(1170 \mathrm{db})$ estimated from in situ velocities.

The EMC volume transport has also been inspected by numerical modeling. A 12-yr modeled mean transport of $30 \mathrm{~Sv}$ has been found by Matano et al. (2002) in a meridional transect off southern Madagascar. Quartly et al. (2006) showed a downstream strengthening of the EMC transport, with mean alongshore transports of 7.9 and $14.8 \mathrm{~Sv}$ at zonal transects off $22^{\circ}$ and $24^{\circ} \mathrm{S}$, respectively. They also found $29.1 \mathrm{~Sv}$ at a meridional transect close to the transect previously inspected by Matano et al. (2002).

Only a few studies hinge on direct observations of velocity. Through a quasi-synoptic survey, where velocities were sampled by lowered acoustic Doppler current profiler (L-ADCP), Nauw et al. (2008) found a volume transport of $30 \mathrm{~Sv}$ at $25^{\circ} \mathrm{S}$. Schott et al. (1988) analyzed 11 months of continuous observations, from three vertical lines of moorings longitudinally aligned off $23^{\circ} \mathrm{S}$, and found a mean (standard deviation) transport of $20.3( \pm 6.6) \mathrm{Sv}$.

Since time series of in situ velocities are scarce, not much is known about the EMC variability. Schott et al. (1988) suggested that the most important variations occur in the 40- to 55-day period band, but such fluctuations contributed only $15 \%$ to the total variance. These authors did not explore the forcing of such a period of variability since their main focus was on explaining why an annual cycle was not detected in the volume transport time series, despite the wind showing an important annual signal.

Warren et al. (2002), analyzing data from current meters deployed at $20^{\circ} \mathrm{S}$ in deep waters of the Mascarene basin, found a bimonthly undulation that propagates westward at $7 \mathrm{~cm} \mathrm{~s}^{-1}\left(6 \mathrm{~km} \mathrm{day}^{-1}\right)$. The authors attributed this variability to barotropic Rossby waves forced by local wind stress curl at one of the resonant frequencies of the basin. Weijer (2008) determined the free oscillatory modes for the same region by performing normal mode analysis and reinforced that the mode that agrees best with the bimonthly fluctuations can also be interpreted as a barotropic Rossby basin mode. However, while Warren et al. (2002) argued that such undulation is driven by mode-2, Weijer (2008) found the mode- 1 resonance period as the source of this variability. 
According to de Ruijter et al. (2005), strong variability around the intraseasonal scale is not just a local phenomenon in the SWIO, but it can also be associated with the basin- and global-scale circulations and their respective variabilities, which propagate sea surface height anomalies westward (Schouten et al. 2002a). Also, eddies reaching the region with frequencies of around five per year have been connected with the equatorial region (Schouten et al. 2002b; Palastanga et al. 2006) and with baroclinic instability of the South Indian Ocean Countercurrent (SICC; Palastanga et al. 2007).

Regarding the vertical structure of the EMC system, at intermediate depths (around $1300 \mathrm{~m}$ ), beneath the surface current and hugging the continental slope, an equatorward undercurrent was first reported by Nauw et al. (2008). More recently, a detailed study of this East Madagascar Undercurrent (EMUC) estimated a mean equatorward volume transport to be $1.33( \pm 1.41) \mathrm{Sv}$, with maxima up to $6 \mathrm{~Sv}$ (Ponsoni et al. 2015a). An equatorward undercurrent has also been reported in the AC system (Beal and Bryden 1997, 1999; Beal 2009) and in the MC (de Ruijter et al. 2002; DiMarco et al. 2002; van Aken et al. 2004), while a poleward undercurrent was reported to occur below and opposite to the northward NMC (Ponsoni et al. 2015b).

In this context, the flows through the MC and off eastern Madagascar are important players of the climate system not only as sources of the AC but also because of their contribution to the upstream control of the AC retroflection. For more than a decade the flow through the MC has been observed with an array of moorings deployed and maintained by the Royal Netherlands Institute for Sea Research (NIOZ; Ridderinkhof et al. 2010; Ullgren et al. 2012). Such long-term direct observations of the EMC system were still lacking, and the following sections intend to describe the EMC synoptic flow and the variability associated with this western boundary current.

This paper is organized as follows: the dataset description and data processing are addressed in section 2; the EMC is described in terms of its mean flow, observed velocities, volume transport and variability in section 3 ; a 21-yr altimeter-based time series of surface geostrophic velocity is explored in section 4; and, last, section 5 presents the discussion and conclusions obtained by this study.

\section{Data and data processing}

\section{a. INATEX moorings: Instrumentation and data return}

In early October 2010, an array of five moorings was deployed across the continental slope off the southeastern coast of Madagascar (Fig. 1), immediately north of $23^{\circ} \mathrm{S}$, in the scope of the project Indian-Atlantic Exchange in present and past climate (INATEX). From inshore to offshore, the moorings are named EMC1 to EMC5. The distances from the coast for every deployment are 6.3 (EMC1), 18.6 (EMC2), 44.8 (EMC3), 58.7 (EMC4), and $110.8 \mathrm{~km}$ (EMC5). The location of the INATEX array is near to the mooring array deployed and maintained from October 1984 to September 1985 by Schott et al. (1988).

A sketch of the mooring array is presented in Fig. 2a. All five moorings carried an upward-looking acoustic Doppler current profiler (ADCP) mounted in the top buoy, intended to sit at $500 \mathrm{~m}$ below the surface, to measure currents in this depth range where the flow is normally strongest and markedly sheared. Additionally, two moorings (EMC2 and EMC3) on the shoremost side of the array were equipped with an upward-looking ADCP in a frame positioned at about $13 \mathrm{~m}$ above the seabed.

The moorings EMC3, EMC4, and EMC5 were also equipped with recording current meters (RCM) placed inline along the mooring cables at the nominal depths of 1000 and $1500 \mathrm{~m}$, supplying point measurements of current velocity. In addition, EMC4 had RCMs at depths around 2000 and $3000 \mathrm{~m}$ (at $800 \mathrm{~m}$ above the seabed), while EMC5 was equipped with RCMs at depths around 2000 and $4000 \mathrm{~m}$ (near to the seabed).

RCM and ADCP sample rates were set to 20 and 30 min, respectively. RCM devices remained operational until the middle of March 2013, except for the RCMs at EMC3 at $1500 \mathrm{~m}$ and at EMC4 at $2000 \mathrm{~m}$, which worked properly until the end of September 2012. The upper ADCP at EMC3 failed for the whole period because of the leakage and internal damage caused by the acid from the batteries, while all the other ADCPs sampled continuously from the deployment until the mooring recovery in April 2013. Therefore, time series from 16 instruments (6 ADCPs and $10 \mathrm{RCMs}$ ) are used in this study.

\section{b. Mooring data processing}

Subsequent to the removal of bad-quality data, the series were synchronized and truncated from 7 October 2010 to 12 March 2013, accumulating approximately $2.5 \mathrm{yr}$ (888 days) of data. This is except for the two RCMs that worked only until September 2012, from whereon we treat the mooring array without these two instruments.

With the aim to remove tidal and near-inertial motions from the time series, all current velocity records went through low-pass filtering (forward-backward Butterworth filter), with a 3.5-day cutoff period, as suggested in the literature (Ridderinkhof et al. 2010; 

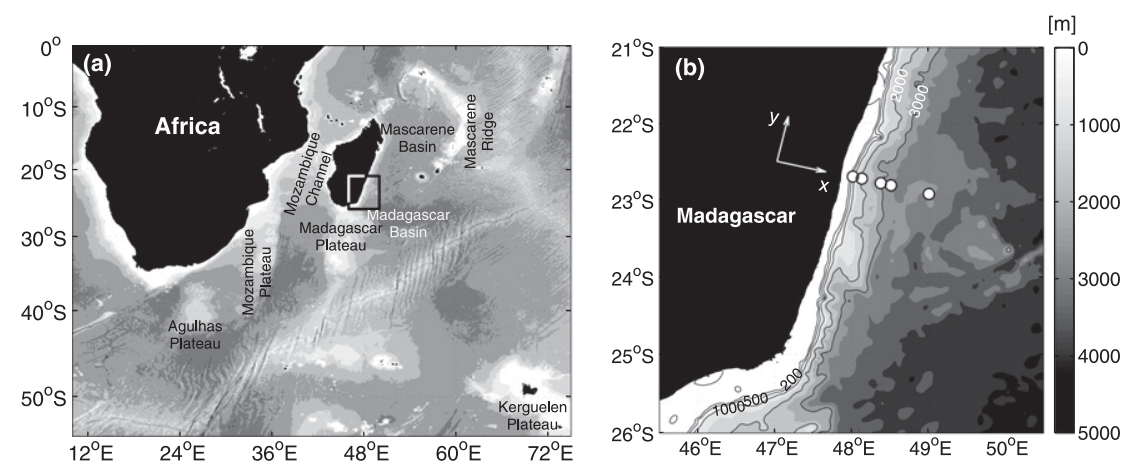

FIG. 1. (a) Map of the southwest Indian Ocean. The main geomorphological features are highlighted in the plot. (b) Zoom of the area of study demarcated by the square drawn in (a). Bathymetric contours are drawn in shades of gray (depth indicated in meters). The white circles represent the geographical location of the INATEX moorings (EMC1-EMC5, from inshore to offshore). The plotted axes indicate the rotation of the coordinate system in alongshore $y$ and cross-shore $x$ directions.

Ullgren et al. 2012). The data were subsampled daily at noon. Meridional and zonal velocities were oriented, respectively, parallel $v$ and perpendicular $u$ to the coast after a clockwise rotation of $12.9^{\circ}$ from north (Fig. 1b). By convention, negative and positive values of the alongshore $v$ component represent a poleward and equatorward flow, respectively.

Velocity data from the upper layer (approximately from $50-\mathrm{m}$ depth to the surface, illustrated by the red shaded region in Fig. 2a) are missed due to limited instrument resolution and near-surface loss typically presented by upward-looking ADCPs. To fill in this gap, velocity data were vertically extrapolated toward the surface onto 8-m cells (ADCP vertical resolution) at standard depth levels $(0,8,16 \mathrm{~m}$, etc. $)$ through an interactive process. For this, the mean vertical shear from the four uppermost sampled depth levels is extrapolated to fill in the next upper grid point, and the process is repeated until the uppermost bin is reached. The method is applied at every time span and individually for all mooring positions, except at EMC3 where the uppermost measurement is around $1000 \mathrm{~m}$. This method was motivated by the geostrophic velocity calculated from the thermohaline field observed during the deployment and redeployment cruises, which shows the velocity to be increasing in magnitude toward the surface (Fig. 2b).

We compare the velocity time series from different depths and moorings in order to guide spatial interpolation (Ridderinkhof et al. 2010). To do so, cross correlations are calculated and the hypothesis of no correlation is tested by use of the $p$ value test (Fig. 2c). Each $p$ value represents the probability of getting a true correlation $(p$ value $=0$ ) by random chance. The correlations are significant, for a $95 \%$ confidence interval, when the $p$ value is smaller than 0.05 . Overall, high and significant positive correlations are obtained among series from the same mooring (pairs highlighted by white circles in Fig. 2c). Because of this strong vertical correlation, the time-synchronized data from ADCPs and RCMs were first linearly interpolated vertically onto 8-m bins.

An important exception to this good vertical correlation is seen at EMC2, since the series from the ADCP placed at $1600 \mathrm{~m}$ (Fig. 2c, red star and black dashed area) captured a flow reversal associated with the equatorward EMUC (Ponsoni et al. 2015a). Velocities are also linearly interpolated between the two ADCPs in this mooring line because we noticed that velocities at the uppermost bin from EMC2-1600 both decay to zero and slightly increase their correlation with the lowest measurements from EMC2-0500.

Strong positive correlations are also found between pairs of series extracted from the region near the EMC core (highlighted by black circles in Fig. 2c). Green and yellow dashed areas in Fig. 2c show that the instruments placed at EMC5 have good correlation only among themselves, suggesting that the mooring array was well designed to capture the EMC flow, since this mooring was placed offshore of the EMC domain during most of the time.

Subsequently, the data from the moorings are horizontally merged by the linear interpolation applied for each standardized 8-m depth level onto a horizontal grid of $1 \mathrm{~km}$. Notice that this interpolation also fills in the empty region created by the malfunctioning of the faulty ADCP at EMC3 (Fig. 2a). Other methods of interpolation were attempted to fill in this gap, as, for instance, the tapered linear interpolation scheme suggested by Ridderinkhof et al. (2010), but our simple 

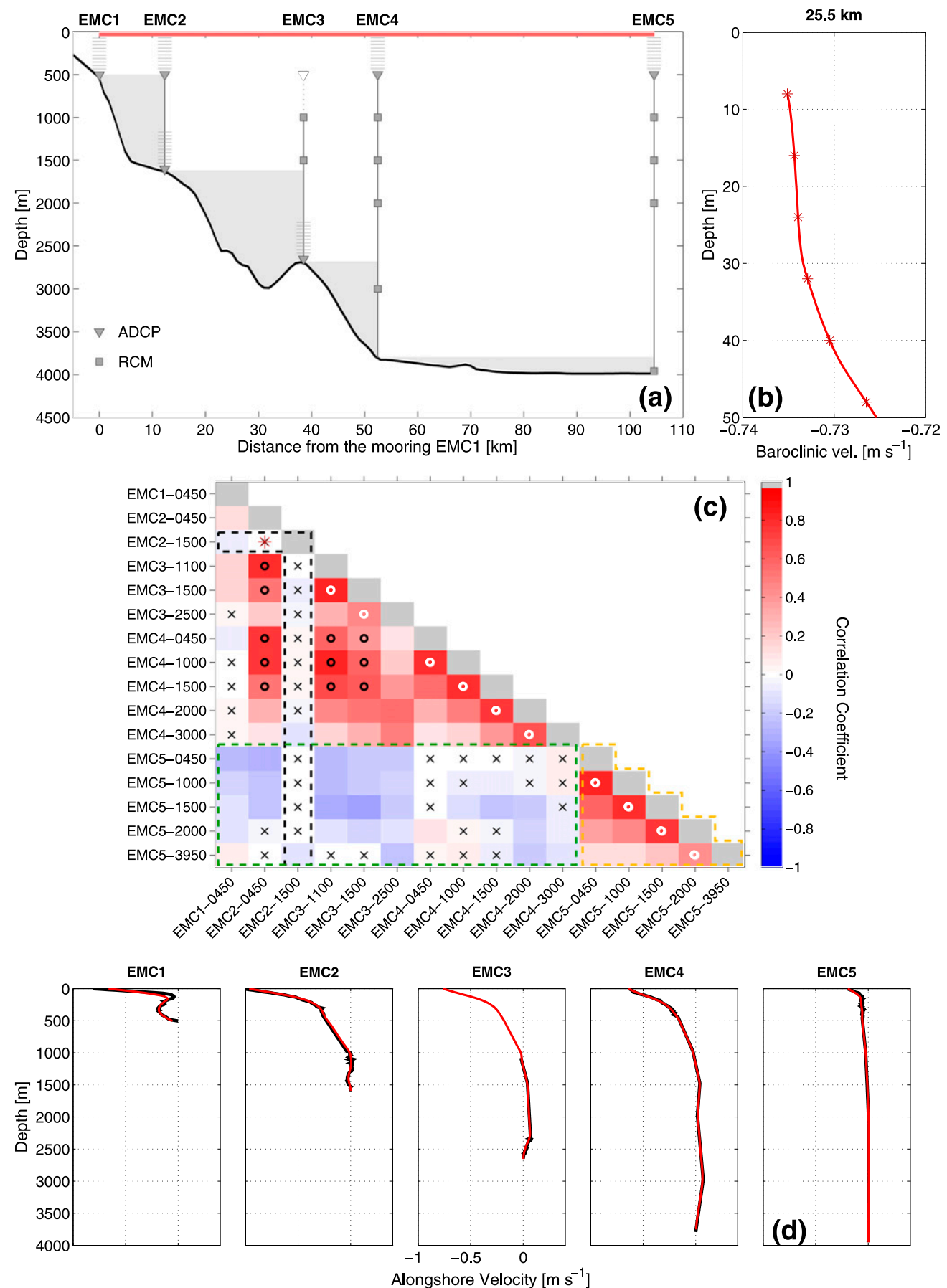

FIG. 2. (a) Sketch of the INATEX moorings where ADCPs and RCMs are represented by triangles and squares, respectively. The small horizontal lines over the triangles represent the upward-looking range of the ADCPs and the empty triangle at EMC3 shows the faulty instrument. The gray shaded areas (near the slope) and the red area (near the surface) show regions where extrapolation is applied. (b) Geostrophic velocity estimated in between EMC2 and EMC3 (at $25.5 \mathrm{~km}$ from EMC1) with in situ thermohaline profiles used to guide extrapolations toward the surface [red area in (a)]. (c) Correlation matrix between pairs of velocity time series from all instruments. White and black circles highlight high correlation between time series from vertically adjacent instruments and time series from instruments near the EMC core, respectively. Black crosses display not significant correlation. Regions highlighted by yellow and green dashed lines indicate low (or not significant) correlation between time series from EMC5 and the time series from the other moorings. Black dashed line and red star indicate the low (or not significant) correlation between the velocity from EMC2-1500 and the other instruments due to the reversal of the flow associated with the EMUC. (d) Timeaveraged profiles of alongshore velocity achieved with full-slip (black) and optimal extrapolations (red). 

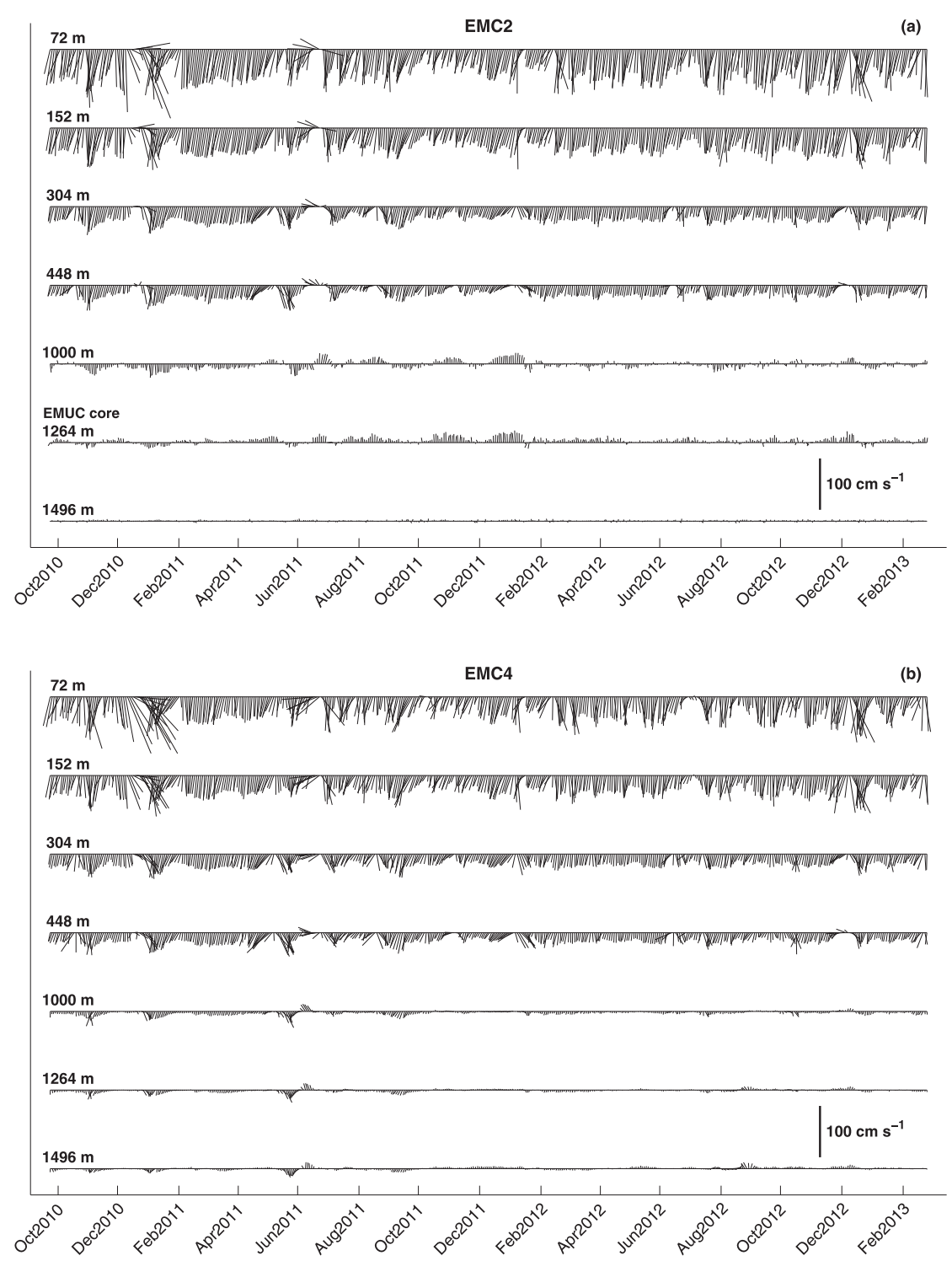

FIG. 3. Velocity vectors from moorings (a) EMC2 and (b) EMC4 at depths of 72, 152, 304, $448,1000,1264$, and $1496 \mathrm{~m}$, plotted every 2 days. Ticks on the $x$ axis are placed at noon on the fifteenth day of the respective month. The vectors are rotated in cross-shore-alongshore coordinates.

horizontal interpolation presented better results with respect to preserving spatial gradients. Hence, the final crossshore grid resolution is $1 \mathrm{~km}$ (distance) $\times 8 \mathrm{~m}$ (depth).

Next, bottom extrapolation was performed to fill in empty data regions created between every pair of neighboring moorings and the bathymetry below the shallowest station of this pair (Fig. 2a, gray shaded areas). Initially, two opposite options are considered: (i) assume that velocities decrease linearly to zero at the continental slope, obeying a no-slip boundary condition, and (ii) extrapolate horizontally the nearest measurement up to the continental slope, accomplishing a fullslip boundary condition (Beal and Bryden 1997; Nauw et al. 2008; Beal 2009). For the sake of completeness, we apply both boundary conditions to our observations as well as a third method where empty regions are gridded with an (iii) optimal interpolation scheme (Carter and Robinson 1987; da Silveira et al. 2004). The reader is referred to Ponsoni et al. (2015a) for a detailed description of the method (iii) applied to our data. Later in section 3b, the results will show that this extrapolation step has minor impact on the computation of the EMC transport, although it deserves special attention in the study of the EMUC, as explored by Ponsoni et al. (2015a). Figure 2d shows the time-averaged profiles of alongshore velocity, at every mooring, achieved with full-slip and optimal extrapolation. 
TABLE 1. Mean velocities and standard deviations $\left(\mathrm{cm} \mathrm{s}^{-1}\right)$ of the EMC at the EMC2 and EMC4 moorings at several depths (m). Alongshore and cross-shore velocity components are represented by $v$ and $u$, respectively. The alongshore axis is rotated $12.9^{\circ}$ from north. The statistics are based on a total of 888 days.

\begin{tabular}{|c|c|c|c|c|c|c|c|c|}
\hline \multirow[b]{2}{*}{ Depth } & \multicolumn{2}{|c|}{$\operatorname{EMC} 2(v)$} & \multicolumn{2}{|c|}{$\mathrm{EMC} 4(v)$} & \multicolumn{2}{|c|}{$\operatorname{EMC} 2(u)$} & \multicolumn{2}{|c|}{ EMC4 $(u)$} \\
\hline & Mean & Std dev & Mean & Std dev & Mean & Std dev & Mean & Std dev \\
\hline 72 & -54.99 & 20.43 & -42.30 & 17.50 & -6.41 & 10.50 & -3.55 & 13.76 \\
\hline 152 & -42.24 & 14.13 & -34.97 & 12.87 & -6.22 & 7.34 & -4.35 & 9.71 \\
\hline 304 & -25.78 & 9.10 & -23.11 & 7.50 & -4.55 & 6.14 & -3.80 & 7.70 \\
\hline 448 & -19.34 & 9.28 & -18.54 & 8.34 & -3.94 & 6.55 & -3.72 & 8.83 \\
\hline 1000 & -2.04 & 8.13 & -4.45 & 4.76 & -0.24 & 1.32 & -1.38 & 3.19 \\
\hline 1264 & 3.93 & 6.24 & -2.04 & 4.08 & -0.42 & 1.45 & -0.75 & 2.52 \\
\hline 1496 & 0.70 & 1.70 & -0.08 & 3.79 & 0.23 & 1.12 & -0.23 & 2.41 \\
\hline
\end{tabular}

\section{c. Supplementary data sources}

We noticed during the deployment cruise that the bottom topography strongly differed from the bathymetry databases. Thus, bathymetry values were time recorded from the onboard echosounder every $5 \mathrm{~min}$ (see bathymetric contours in Fig. 2a).

As mentioned above, in order to guide extrapolations of the velocities sampled by the 500-m upward-looking ADCPs from their maximum reach (minimum depth) until the surface (approximately the upper $50 \mathrm{~m}$ of water column), a vertical profile of geostrophic velocity was calculated in between EMC2 and EMC3 (Fig. 2b) based on the thermohaline structure sampled by CTD during the deployment and redeployment cruises at the position of the moorings EMC2 and EMC3.

At daily resolution, a 21-yr (from 1 January 1993 to 31 May 2014) altimeter-based time series of absolute dynamic topography (ADT), sea level anomaly (SLA), and surface absolute and anomaly geostrophic velocities estimated from both ADT and SLA, respectively, are used in this work. The altimeter products were produced by Ssalto/ Duacs and distributed by AVISO (http://www.aviso. altimetry.fr/duacs/), with support from CNES. Here, we use the daily data from the "all sat merged" series of the delayed time altimeter product, which is provided with a spatial resolution of $0.25^{\circ}$. The ADT product results in adding SLA to the new mean dynamic topography (MDTCNES-CLS13) produced by the CLS Space Oceanography Division as an estimate of the ocean sea surface height above the geoid for the 1993-2012 period (Rio et al. 2014).

\section{In situ observations of the East Madagascar Current}

\section{a. Observed velocities, mean flow, and mesoscale activity}

The in situ measurements from the INATEX moorings indicate a strong western boundary current with some meandering activity, as represented by the stick plot of velocities in Fig. 3. A reversal of the flow is observed near the surface at EMC2 (Fig. 3a) only twice and for different reasons (see explanation below): around the transition December 2010-January 2011 and at the beginning of July 2011.

The current is crossing the transect slightly inclined toward the coast at EMC2, while the flow is more perpendicular to the transect at EMC4 (Fig. 3b). Statistics displayed in Table 1 indicate that the mean velocities of the alongshore component $\left(-55.0\right.$ and $-42.3 \mathrm{~cm} \mathrm{~s}^{-1}$ at EMC2 and EMC4) are more than 8 times stronger than the mean cross-shore component $\left(-6.4\right.$ and $-3.5 \mathrm{~cm} \mathrm{~s}^{-1}$ ) near the surface. Large differences are also found at other depths (Table 1).

The vertical shear shown in Fig. 3 and Table 1 highlights the velocity decay from the surface to approximately $1000 \mathrm{~m}$, where the velocity field is close to its mean level of no motion $\left(0 \mathrm{~cm} \mathrm{~s}^{-1}\right.$ isotach in Fig. $\left.4 \mathrm{a}\right)$. In the vicinity of $1260 \mathrm{~m}$ at EMC2 (Fig. 3a), up on the continental slope, there is a reversal in the flow associated with the equatorward EMUC.

Hereinafter, the grid point where the EMC has its strongest velocity value will be referred to as the core. The real current core at every moment is likely missed due to the horizontal spacing between neighboring moorings. The global maximum velocity was measured on 23 December 2010, when the EMC core presented speeds up to $-172 \mathrm{~cm} \mathrm{~s}^{-1}$ at the EMC2 location. However, this value is an exception since velocities stronger than $-150 \mathrm{~cm} \mathrm{~s}^{-1}$ were rarely observed (during 6 of 888 days). Velocities stronger than $-100 \mathrm{~cm} \mathrm{~s}^{-1}$ were sampled on 119 days ( $\sim 13 \%$ of the whole time span), while most of the core values lie in the range of -50 and $-100 \mathrm{~cm} \mathrm{~s}^{-1}$ (698 days, $\sim 79 \%$ of the whole time span).

The EMC presents a mean core with a velocity of $-79( \pm 21) \mathrm{cm} \mathrm{s}^{-1}$, which is found close to the surface at EMC2 (Fig. 4a). Only on a few occasions was the EMC core sampled offshore in moorings EMC4 or EMC5 (for instance, Fig. 4b), during 24 and 17 days, respectively. 

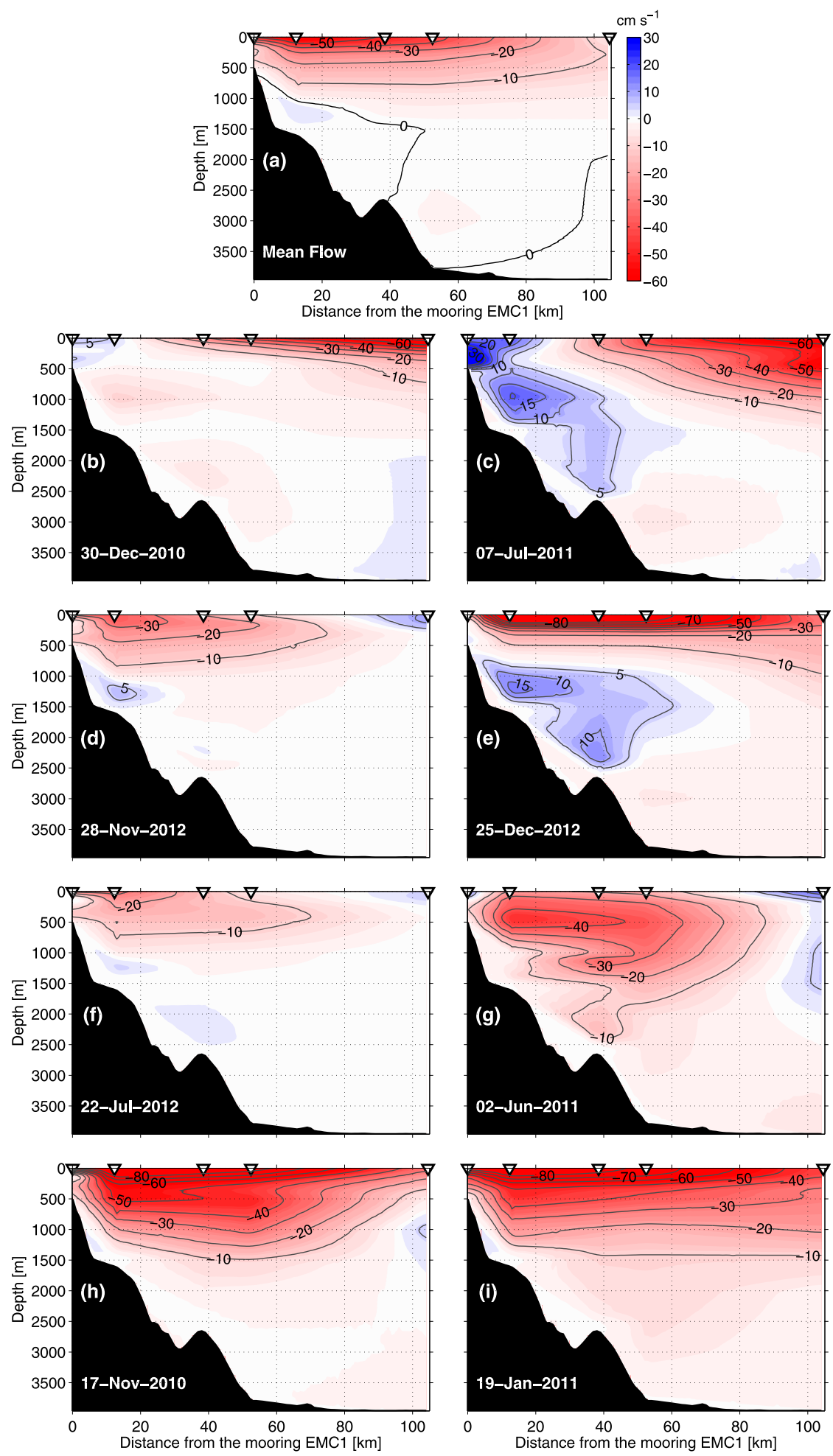

FIG. 4. (a) Alongshore mean flow and (b)-(i) alongshore velocities observed at eight different moments. Notice that the panels are not placed in chronological order but according to the sequence that they are discussed in the text. The red shades represent poleward velocities, while the blue shades indicate equatorward velocities. 
TABLE 2. Volume transport (Sv) calculated from different extrapolation methods [no slip (NS), full slip (FS), and optimal interpolation (OI)] and different integration criterion (NVT and IDVT).

\begin{tabular}{lccc}
\hline \hline & NS & FS & OI \\
\hline NVT: bottom-surface & $-18.3( \pm 8.5)$ & $-18.6( \pm 8.9)$ & $-18.3( \pm 8.4)$ \\
NVT: $1500 \mathrm{~m}-$ surface & $-17.8( \pm 6.8)$ & $-18.1( \pm 7.0)$ & $-17.8( \pm 6.8)$ \\
IDVT: $0 \mathrm{~cm} \mathrm{~s}^{-1}$ isotach & $-20.6( \pm 7.6)$ & $-21.2( \pm 7.9)$ & $-20.5( \pm 7.5)$ \\
IDVT: $10 \mathrm{~cm} \mathrm{~s}^{-1}$ isotach & $-16.0( \pm 6.8)$ & $-16.4( \pm 7.0)$ & $-16.0( \pm 6.8)$ \\
\hline
\end{tabular}

Figures $4 \mathrm{~b}$ and $4 \mathrm{c}$ display the two moments when a reversal of the flow is registered in Fig. 3. The daily sequence of plots (not presented) shows the equatorward flow related to the first event growing from the coast and vanishing at depths greater than $500 \mathrm{~m}$ at the same moment as the EMC migrates offshore. However, we do not have a clear explanation of the forcing of this reversal. The second reversal is more pronounced, and an equatorward flow is observed over the entire water column. It results from the passage of a cyclonic eddy coming from the EMC upstream region. In section 4, we will discuss the impact of cyclonic eddies arriving from the east to the offshore edge of this western boundary current.

An outstanding contribution of the baroclinic component to the geostrophy of the EMC system is suggested in Figs. $4 \mathrm{~d}-\mathrm{f}$. For instance, in Fig. 4e a strong poleward surface current appears concomitantly with a strong equatorward undercurrent, while in Figs. $4 d$ and 4f a weak surface and a weak undercurrent coexist. Additionally, Fig. 4f shows an occasion when the EMC flow was exceptionally weak and consequently the integrated volume transport through the INATEX transect was nearly zero (see section $3 b$ ).

However, this scenario is not always observed, since there are moments when the baroclinic contribution is weaker, while the barotropic component increases, as suggested in Figs. 4g-i. At these moments, when a robust poleward barotropic flow contributes to an increasing volume transport, the EMC migrates deep into the water column, masking the equatorward flow at intermediate levels. Therefore, the EMUC is virtually absent in the velocity time series at these moments (Ponsoni et al. 2015a). Notice that the $-10 \mathrm{~cm} \mathrm{~s}^{-1}$ isotach reaches down to about $1500 \mathrm{~m}$ in Figs. $4 \mathrm{~g}-\mathrm{i}$.

Figure $4 \mathrm{~g}$ highlights an unusual scenario where the EMC core is not found close to the surface but is rather shifted to around 450-m depth. Only on nine other days was the EMC core found deeper than $50 \mathrm{~m}$. This figure also stresses a deep excursion of the entire EMC structure. For instance, the $-10 \mathrm{~cm} \mathrm{~s}^{-1}$ isotach reached $2500-\mathrm{m}$ depth at EMC3.

Figures $4 \mathrm{~h}$ and $4 \mathrm{i}$ show the cross-shore transects in which the EMC attained maximum transport over our time series. In both cases, maximum observed velocity was around $-98 \mathrm{~cm} \mathrm{~s}^{-1}$. However, besides this similarity, the computed EMC transport was $5 \mathrm{~Sv}$ stronger on 19 January 2011 (Fig. 4i), since at this occasion the EMC was wider than on 17 November 2010 (Fig. 4h) as indicated by the isotachs in both panels.

\section{b. Volume transport}

To calculate the volume transport, two methodological issues have to be addressed. First, extrapolations are necessary to fill in empty data regions highlighted by the gray shades in Fig. 2a, as already detailed in section $2 \mathrm{~b}$. Second, we have to select the grid points, at every time span, in which velocity values will be computed for the transport calculations.

Regarding the first issue, the results indicate that the chosen method (no slip, full slip, or optimal interpolation) for gridding empty areas has minor

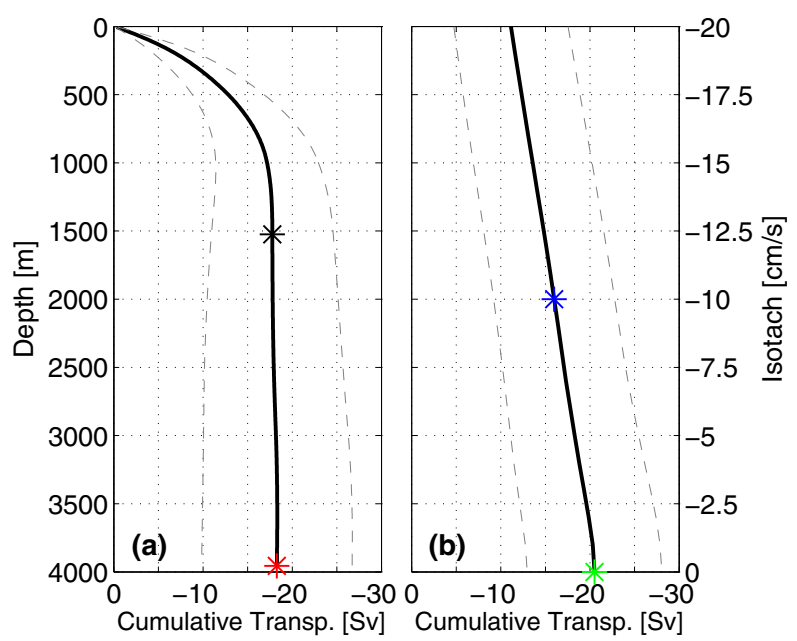

FIG. 5. Mean EMC volume transport calculated with two methods. (a) NVT, where both negative (poleward) and positive (equatorward) values of velocity are computed in the transport calculation. The black curve represents the cumulative mean transport from the surface to a certain depth ( $y$ axis). (b) IDVT, where only grid points with negative values (poleward flow) enclosed by a specific isotach ( $y$ axis) are computed in the transport calculation. Gray dashed lines represent the standard deviation. The stars highlight the mean values of the time series plotted in Fig. 6. 


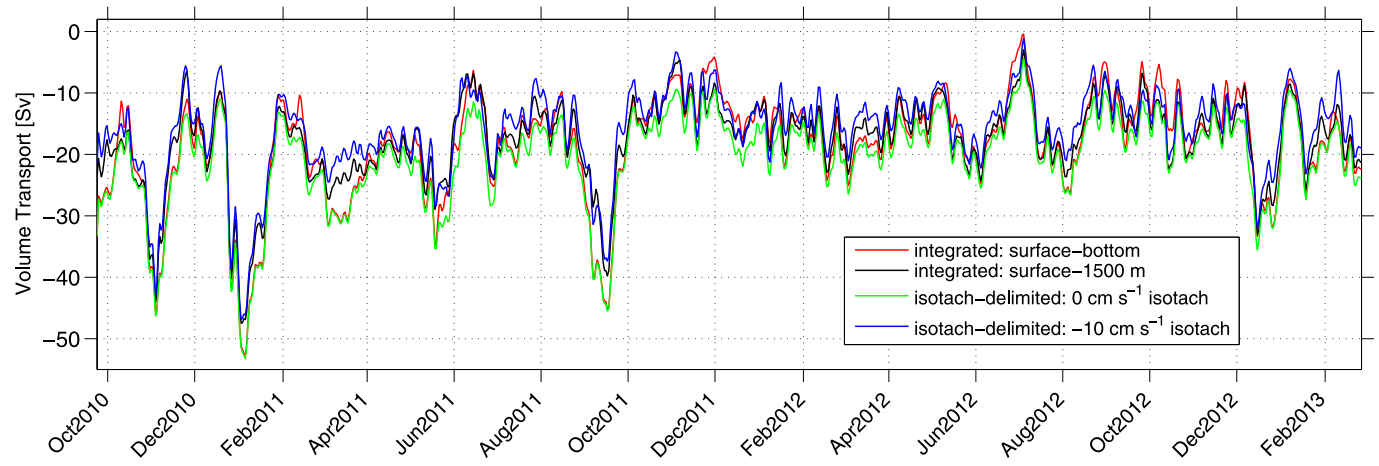

FIG. 6. Volume transport time series: integrated volume transport from the bottom (red) and $1500 \mathrm{~m}$ (black) to the surface estimated with both negative (poleward) and positive (equatorward) values of velocity; isotachdelimited volume transport estimated through the poleward flow (only negative values of velocity) delimited by the isotachs of -10 (blue) and $0 \mathrm{~cm} \mathrm{~s}^{-1}$ (green). Ticks on the $x$ axis are placed at noon on the fifteenth day of the respective month.

impact on the volume transport calculations, since most of the flow related to the EMC is not crossing those regions (cf. Fig. 2a with Fig. 4). Notice in Table 2 that the average errors from different methods are smaller than $0.5 \mathrm{~Sv}$. We use the velocity fields extrapolated through optimal interpolation to plot figures and for further discussions in this paper.

Regarding the second issue, we adopted two general options to guide the selection of points that will be used to compute the volume transport: (i) net volume transport (NVT), where both positive and negative velocity values integrated from a certain depth to the surface are considered, and (ii) isotach-delimited volume transport (IDVT), where only grid points with negative values (poleward flow), enclosed by a specific isotach, are computed. The motivation for this latter choice is that this may represent a flow having different water mass properties.

Figure 5a shows the mean NVT integrated from different depths. For instance, the black and red stars indicate a poleward (therefore, negative) mean NVT of $-17.8( \pm 6.8) \mathrm{Sv}$ and $-18.3( \pm 8.4) \mathrm{Sv}$ for the upper $1500 \mathrm{~m}$ and for the whole water column, respectively. Figure $5 \mathrm{~b}$ shows a mean IDVT of $-16.0( \pm 6.8) \mathrm{Sv}$ and $-20.5( \pm 7.5) \mathrm{Sv}$ calculated with the isotachs of $-10 \mathrm{~cm} \mathrm{~s}^{-1}$ (blue star) and $0 \mathrm{~cm} \mathrm{~s}^{-1}$ (green star) as limits, respectively.

Figure 6 shows the complete transport time series calculated for the four different cases discussed in the previous paragraph and highlighted with the stars in the mean scenario, shown in Fig. 5 and Table 2. Notice that besides the differences in the transport values, all time series have the same pattern of variability.

During three short periods, the EMC is marked by a large volume transport: around 17 November 2010, 19 January 2011, and 30 September 2011 the EMC transport reached up to $-45.6,-52.8$, and $-45.2 \mathrm{~Sv}$, respectively (NVT, integrated from bottom to surface, red line in Fig. 6). In the strongest event, the EMC transported over 50 Sv from 12 January 2011 to 20 January 2011. Such strong volume transports, reaching up to $-40 \mathrm{~Sv}$, are unusual and occur only during 3\% (26 of 888 days) of the entire time span. Transport values in the intervals of $(-40,-30),(-30,-20),(-20,-10)$, and $(-10,0)$ Sv were sampled during 51, 211, 488, and 112 days, respectively.

A notable minimum poleward transport of $0.4 \mathrm{~Sv}$ was observed on 18 July 2012. From 14 to 19 July 2012, the transport values were reduced to less than $3 \mathrm{~Sv}$. The reduced transport around this period is effectively a consequence of a weak current rather than an artifact of the EMC meandering offshore the INATEX moorings (Fig. 4f). Such small transport was not observed again from October 2010 to March 2013.

\section{c. Transport variability}

Wavelet analysis (Fig. 7b) of the EMC transport time series (Fig. 7a) reveals a clear nearly bimonthly period band of variability, which dominates the global spectrum when integrated over time (Fig. 7c). This period is centered at 66 days (frequency $5.5 \mathrm{yr}^{-1}$ ) but is also significant over the band from 45 to 85 days, corresponding with a frequency band of 4.3 to 8.1 peaks per year.

As an additional analysis, we estimate the NVT for every 8-m vertical layer (see mean values per layer in Fig. 8a) and so apply the wavelet analysis for the individual time series. Figure $8 \mathrm{~b}$ indicates that the bimonthly signal is surface intensified but still significant in the upper 1000-1500-m depth.

This dominant band of variability differs from that of the EMUC, which presents stronger variability near the semiannual period band (132-187 days), likely related to some internal mode of variability of the system (Ponsoni et al. 2015a). The EMC transport presented only a slightly significant nearly semiannual peak centered at 155 days (Fig. 7c). 

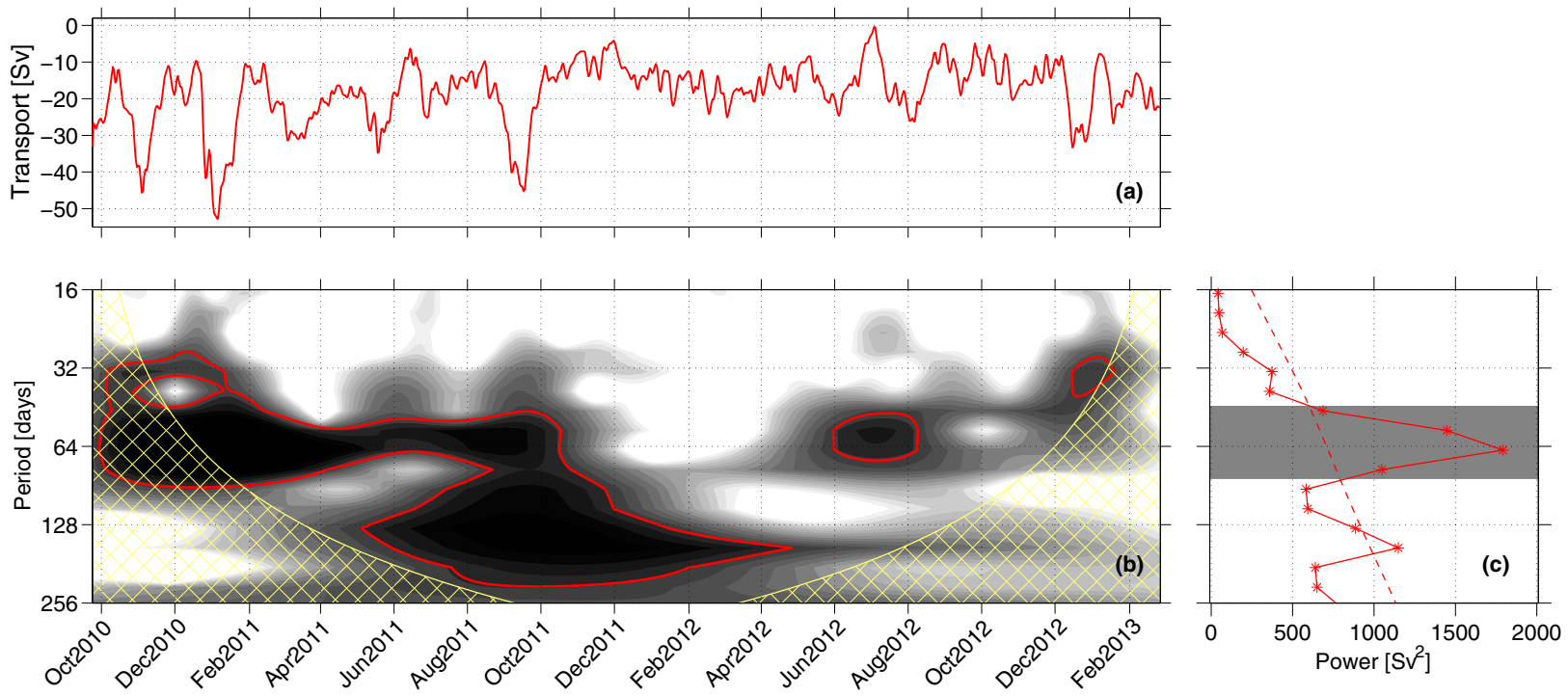

FIG. 7. (a) Volume transport time series (same as red line in Fig. 6). (b) Wavelet power spectrum of the normalized volume transport time series. The red contours denote the $95 \%$ significance levels above a red noise background spectrum, while the cross-hatched areas indicate the "cone of influence" where the edge effects become important. For all cases, the mother wavelet is a Morlet wavelet [see Torrence and Compo (1998) for details]. (c) Time-integrated power spectrum from the wavelet analysis, where the dashed area corresponds to the $95 \%$ significance level. The nearly bimonthly period (45-85 days) is represented by the horizontal gray bar.

After applying a bandpass filter (forward-backward Butterworth filter) adjusted for the bimonthly period (45-85 days), we found that $41 \%$ of the variance of the transport time series can be explained by this band. However, although strong, this variability is not persistent over the whole time series. From the beginning of November 2011 to the middle of June 2012, the bimonthly band does not appear significant in the wavelet spectrum (Figs. 7a,b). During this period of time (here computed from 01 November 2011 to 15 June 2012), the EMC transport time series reduced both on average as well as in standard deviation $[-14.4( \pm 4.3) \mathrm{Sv}]$ when compared to the full record $[-18.3( \pm 8.4) \mathrm{Sv}]$.

The forcing of the nearly bimonthly period as well as an explanation for the absence of this variability in the time span mentioned above are discussed in section $4 \mathrm{a}$.

\section{Altimeter observations of the East Madagascar Current}

To the knowledge of the authors, the INATEX time series represent the longest continuous in situ measurements of the EMC system. This dataset also provides unique horizontal and vertical resolution of the current velocities. Nevertheless, it presents some limitations. For instance, the spatial coverage of the measurements is restricted to the mooring array, which makes answering questions such as "what is the forcing of the nearly bimonthly variability?" hard to assess. In this respect, satellite altimeter observations at ocean basin scale may contribute to our understanding of the EMC system.

\section{a. Forcing of the nearly bimonthly variability}

The combined analysis of altimeter data and in situ observations reveals that the nearly bimonthly variability is strongly related to the SLA field (Fig. 9). Overall, the peaks seen in both the geostrophic velocity estimated
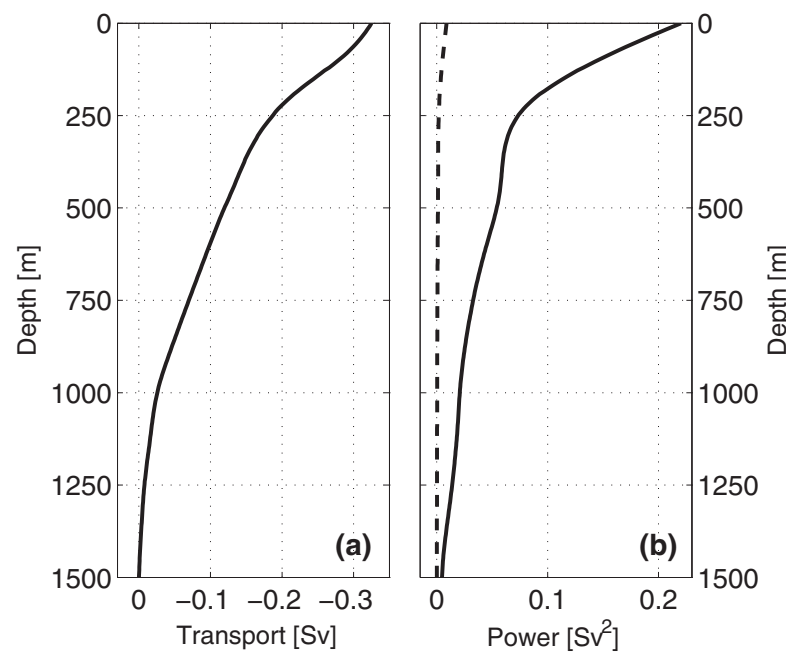

FIG. 8. (a) Time-averaged NVT calculated for every 8-m depth interval perpendicular to the INATEX transect. (b) Power density for the 66-day signal (solid line) from the wavelet analysis (same as in Fig. 7c) and its respective 95\% significance level (dashed line) for every 8 -m vertical bin. 

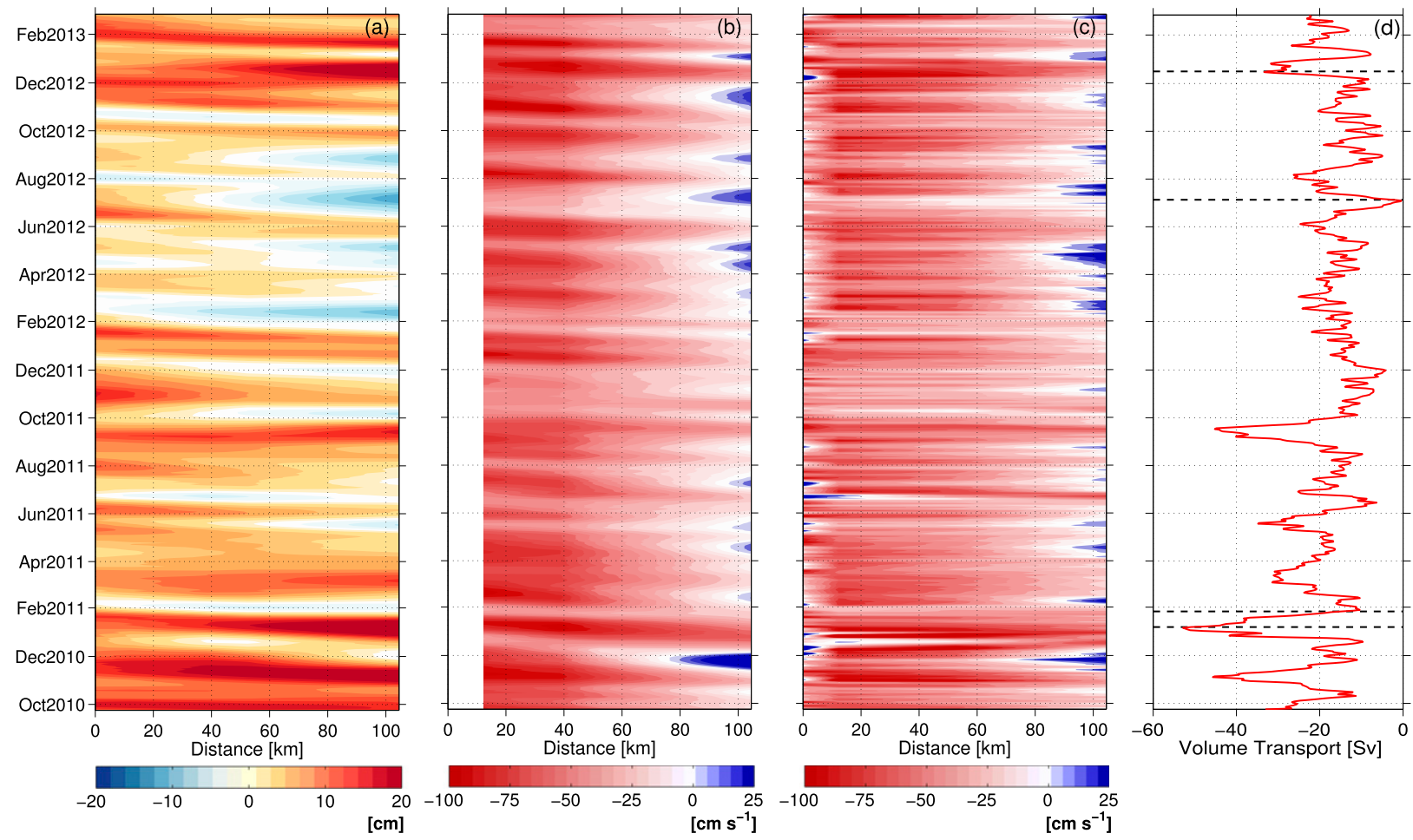

FIG. 9. Distance-time diagrams: (a) SLA, (b) alongshore geostrophic velocity estimated from ADT, and (c) alongshore observed velocities at $75 \mathrm{~m}$ from the INATEX moorings. (d) Volume transport time series (same as red line in Figs. 6 and 7a) from INATEX velocity measurements. Horizontal black dashed lines in (d) indicate the moments when the horizontal fields of sea level anomaly are shown in Fig. 10. In the three first panels, the horizontal scale displayed on the $x$ axis is the distance from EMC1 to EMC5.

from ADT (Fig. 9b) and the in situ velocities (Fig. 9c) and, therefore, in the EMC transport (Fig. 9d) are observed concomitantly with high positive anomalies in the sea level (Fig. 9a).

In dynamic terms, these domes in SLA are represented by anticyclonic eddies (AE). The poleward flow on their landward side potentially increases the EMC flow. On top of this, the presence of the coast creates a mirror image vortex (Shi and Nof 1993, 1994; Kundu and Cohen 2008) that drives the core of the AE poleward. The converse is true for negative anomalies [cyclonic eddies (CE)], which induce an attenuation in the EMC transport (Fig. 9). Again this is because of the landward side of the CE flowing equatorward, while its mirror vortex, because of the presence of the coast, tends to drive the $\mathrm{CE}$ also equatorward.

Figure 10 shows fields of SLAs plotted at four different moments, indicated by black dashed lines in Fig. 9d. On 20 January 2011 (Fig. 10a), a strong positive anomaly is intensifying the EMC transport to its maximum observed during the INATEX program. This event is particularly strong because such a feature results from the merging of two AEs (for the daily sequence of images, the reader is referred to the animations in the supplemental material). On 9 February 2011 (Fig. 10b), right after the passage of the previous $\mathrm{AE}$, a negative anomaly (a CE) is attenuating the EMC transport. On 19 July 2012 (Fig. 10c), a CE induces the EMC transport to its minimum observed during the INATEX program. Notice that at this moment the whole region shown in the map presents reduced SLA values. On 30 December 2012 (Fig. 10d), another AE increases the EMC transport.

Remarkably, for about 3.5 months, from 16 February to 29 May 2012, a large CE maintained its landward branch over the mooring array. During this period, the EMC did not present intense events, since this branch of the eddy was attenuating the EMC and the arrival of AEs was blocked by the quasi-standing CE. This is the reason why the bimonthly variability is absent in the EMC transport (Fig. 7).

The remote origin of the reported quasi-standing $\mathrm{CE}$ was found farther east $\left(62^{\circ} \mathrm{E}, 24^{\circ} \mathrm{S}\right)$ at the beginning of August 2011 (Fig. 11). From its origin to Reunion Island $\left(55.6^{\circ} \mathrm{E}, 23.4^{\circ} \mathrm{S}\right.$, on 29 November 2011$)$, the eddy traveled with a mean velocity of $6.2 \mathrm{~km}$ day $^{-1}$. After passing Reunion Island, the eddy became stronger and traveled with a mean velocity of $9 \mathrm{~km}_{\text {day }}{ }^{-1}$ toward the Madagascar coast until it parked near $50^{\circ} \mathrm{E}$ on 16 February 

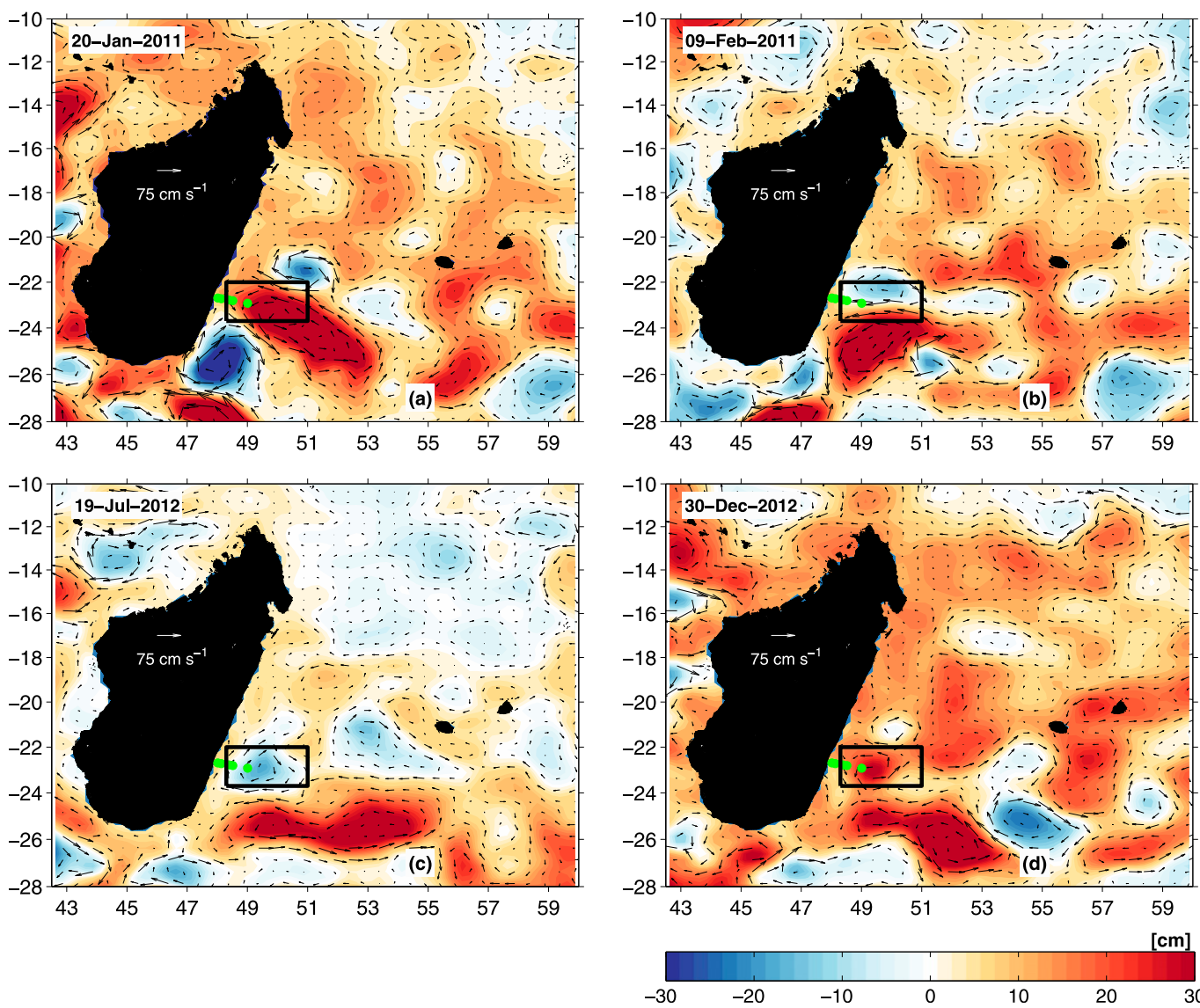

FIG. 10. SLA from satellite altimeter data plotted at four different moments: (a) on 20 Jan 2011 when a strong positive anomaly (anticyclonic eddy) is intensifying the EMC transport to its maximum observed during the INATEX program; (b) on $9 \mathrm{Feb} 2011$ when, right after the passage of the anticyclonic eddy shown in (a), a negative anomaly (cyclonic eddy) is attenuating the EMC transport; (c) on $19 \mathrm{Jul} 2012$ when a cyclonic eddy is inducing the EMC transport to its minimum observed during the INATEX program; and (d) on 30 Dec 2012 when another anticyclonic eddy increases the EMC transport. The green points indicate the position of the INATEX moorings. The black box is discussed in section $4 \mathrm{c}$ and used as a reference to calculate the SLA averages plotted in Fig. 15.

2012. Figure 11 presents the track of the CE from its origin to the parking region, where it disappeared.

Figure 12a shows the alongshore velocities observed at the EMC5 mooring highlighting the period when the quasi-standing $\mathrm{CE}$ was strong enough to induce a reversal of the flow at this location. Figures $12 b$ and $12 c$ show such a cyclonic eddy on 23 February 2012 and on 18 May 2012, respectively.

To investigate the pathway of sea level anomalies that induce the nearly bimonthly variability in the EMC, we calculate the wavelet spectra of SLA time series over the south Indian Ocean and compute the mean power spectra within the defined band (45-85 days, see Fig. $7 \mathrm{c}$ ). The map plotted in Fig. 13 shows that, to the east of the Mascarene Ridge (longitudes to the east of $60^{\circ} \mathrm{E}$ ), the westward-propagating anomalies travel preferentially in a corridor approximately defined by the latitudinal range of $18^{\circ}-24^{\circ} \mathrm{S}$. However, the nearly bimonthly period is strongly intensified in the Mascarene basin, in between the Mascarene Ridge and the southern part of Madagascar Island (Fig. 13). This phenomenon is also visible in the animations provided as supplemental material to this paper.

\section{$b$. The 21 yr of altimeter-based surface volume transport estimates}

In this section, we evaluate how good the match is between the in situ velocities and the absolute geostrophic velocities measured from satellite, and then we derive a long-term altimeter-based time series of surface volume transport. To do so, first we spatially interpolate the altimeter-derived absolute geostrophic velocities to the horizontal INATEX grid positions and subsequently decompose these velocities in the same fashion as done for the in situ velocities (section $2 b$ ) in order to find the alongshore component. 


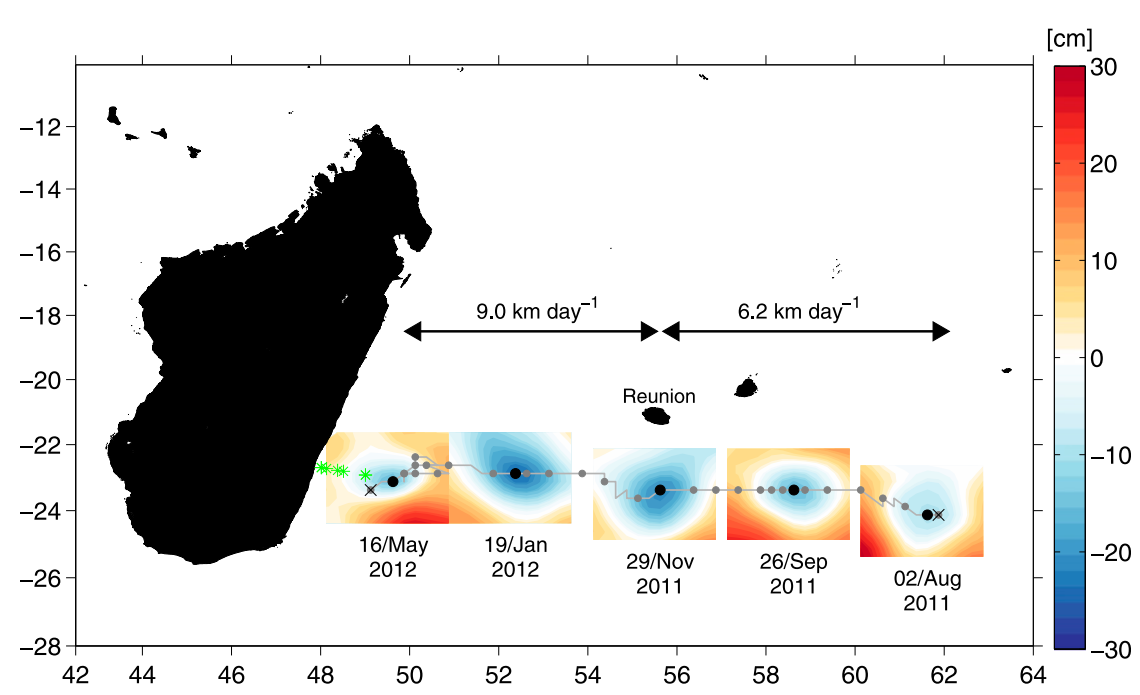

FIG. 11. Origin and track of cyclonic eddy propagating toward Madagascar coast seen through values of SLA. The cyclonic was observed standing offshore the INATEX moorings for about 3.5 months before being dissipated (see Fig. 12). Crosses display the regions of origin $\left(\sim 62^{\circ} \mathrm{E}\right.$ and $24^{\circ} \mathrm{S}$ on 1 Aug 2011$)$ and ending $\left(\sim 49^{\circ} \mathrm{E}\right.$ and $23^{\circ} \mathrm{S}$ on 31 May 2012) of the eddy. Gray line shows the path of the CE, while small gray circles indicate the center of the eddy every 5 days. Black circles represent the cyclonic core at the moments when the contours of SLA are also plotted in the figure. The arrows indicate that the eddy traveled with mean speeds of 6.2 and $9.0 \mathrm{~km} \mathrm{day}^{-1}$ along the track from the origin to Reunion Island and from Reunion Island to its parking location, respectively. The green stars indicate the position of the INATEX moorings.

Second, we calculate the volume transport, from EMC2 to EMC5, assuming that these velocities are uniform over the first $8 \mathrm{~m}$ of the water column so that the grid resolution is equal to the one used for the sampled data $[1 \mathrm{~km}($ distance $) \times 8 \mathrm{~m}($ depth $)]$. We disregard the data inshore of EMC2, since close to the coast the altimeter performance is affected by the landmass, and therefore errors of the altimeter-based geostrophic velocities are typically higher.

Figure 14 shows the surface volume transport calculated from the altimeter-based geostrophic velocities (black line, from October 2010 to March 2013) and from the in situ velocities (red line) over the first 8-m bin. Overall there is a high correlation between both time series, with a correlation coefficient of 0.72 (significant for a $p$ value test). The mean absolute error $(1 / n) \sum_{i=1}^{n}\left|e_{i}\right|$, where the daily error $e_{i}(i=1,2, \ldots, 888)$ is defined by the difference between both variables, is equal to $0.07 \mathrm{~Sv}$. The average (standard deviation) of the poleward surface volume transport from the INATEX in situ observations is $-0.32( \pm 0.13) \mathrm{Sv}$, while the surface transport estimated over the same time span from the altimeter-derived geostrophic velocities presents values of $-0.28(0.09) \mathrm{Sv}$.

For $21 \mathrm{yr}$, the surface transport estimated from the altimeter data exhibits a mean and standard deviation of $-0.31( \pm 0.09) \mathrm{Sv}$ (black full and dashed lines in Fig. 15). The nearly bimonthly variability also shows up in the wavelet spectrum (not shown) of this time series, although there is a strong concentration of energy in the lowfrequency band (interannual, $<1$ cycle per year).

The bandpass filtered time series (forward-backward Butterworth filter) reveals that the interannual and bimonthly variabilities explain about $16 \%$ and $31 \%$, respectively, of the variance found in the 21-yr altimeterbased transport. Therefore, both bands together explain almost half $(47 \%)$ of the total variability. If we take into account only the period when the moorings were deployed, the bimonthly band explains about $40 \%$ of the variance presented by the altimeter-based transport. This is in good agreement with the amount of variance of the in situ transport time series explained by the bimonthly variabilities ( $41 \%$, section $3 \mathrm{c})$.

\section{c. On the interaction of the eddies with the EMC}

Since the most prominent fluctuations in the EMC transport occur because of the arrival of westwardpropagating eddies, we select a region close to the western boundary, where these features are potentially interacting with the EMC, to better comprehend the effects of this interaction. The region is defined by a zonal rectangle delimited by $22^{\circ}-23.7^{\circ} \mathrm{S}$ 

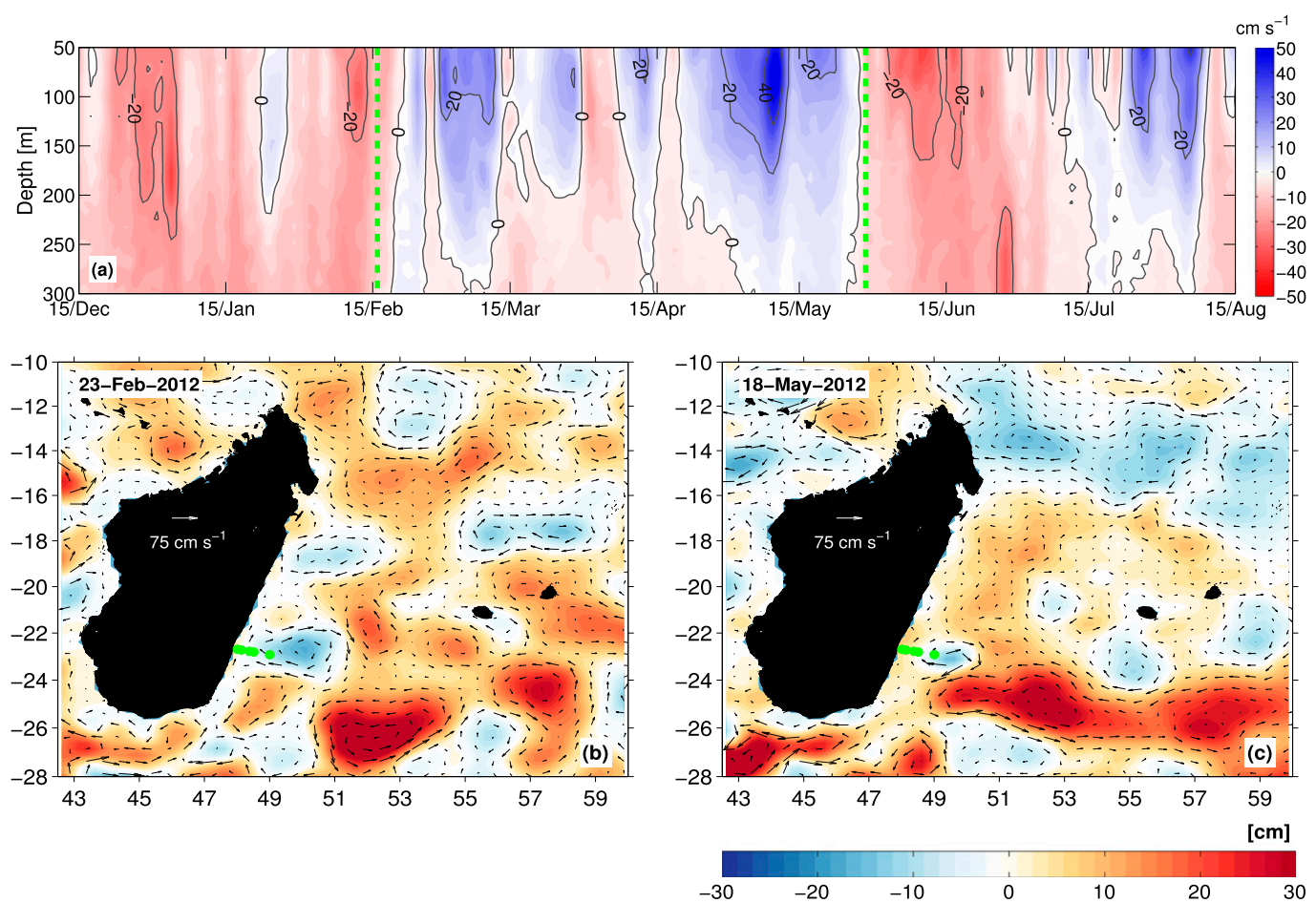

FIG. 12. (a) Alongshore velocities observed at the EMC5 mooring highlighting the period (enclosed by the green dashed lines) when it is possible to observe the quasi-standing cyclonic eddy that stayed in the vicinity of the INATEX moorings for about 3.5 months (from 16 Feb 2012 to 29 May 2012, approximately). (b) SLA from satellite altimetry plotted on 23 Feb 2012 and (c) on 18 May 2012, showing the quasi-standing CE in the region of the INATEX moorings. The green stars indicate the position of the INATEX moorings.

and $48.3^{\circ}-51^{\circ} \mathrm{E}$ (see black rectangle in Fig. 10). The zonal orientation of the rectangle is justified by the fact that most of eddies are observed traveling in a nearly zonal trajectory (e.g., Fig. 11).

Figure 15 compares the time series of the mean SLA from the selected region with the altimeterderived EMC transport. Overall, the figure reinforces that pronounced positive and negative anomalies in the sea level drive strong and weak EMC transport, respectively. Figure 16 shows the scatterplot for the mean SLA versus the surface volume transport estimated from satellite (Fig. 16a) and in situ (Fig. 16b) observations. A significant correlation is found in both diagrams with a coefficient of -0.46 .

Notice in Fig. 15 that only at two occasions is an equatorward reversal of the surface transport observed: from 23 January to 2 February 1993 and from 18 to 23 December 1995. Both reversals are associated with the passage of a strong $\mathrm{CE}$.

The sequence of plots of the SLA fields (and also Fig. 15) shows that the intensification (EMC-AE interaction) or attenuation (EMC-CE interaction) of the EMC transport by mesoscale eddies depend on different factors, as for instance, proximity to the current, residence time, size, and amplitude of the anomalies.

Figure 17 indicates how the arrival of the eddies influences the vertical structure of the EMC. During outstanding events of EMC-AE interactions, here distinguished by the moments when the surface volume transport is stronger than one standard deviation away from its average (Fig. 15), the current migrates deep in the water column, its core is wider and stronger, and the EMUC virtually disappears (Fig. 17a). The opposite occurs during EMC-CE interactions (Fig. 17b).

\section{d. Interannual variability}

Besides the remarkable nearly bimonthly signal, annual averages of the long-term surface transport suggest that interannual variabilities also play a role in the EMC system. For instance, the annual time series show a minimum and maximum poleward transport of 0.26 (2012) and $0.35 \mathrm{~Sv}$ (2009), respectively. Figure 18 suggests three distinct moments: first, from 1993 to 2001, when a reduced transport is observed, with exception of 1994. Second, from 2002 to 2010 , the volume transport is stronger compared to the previous period (exceptions are 2005 and 2007). Finally, the third period covers 


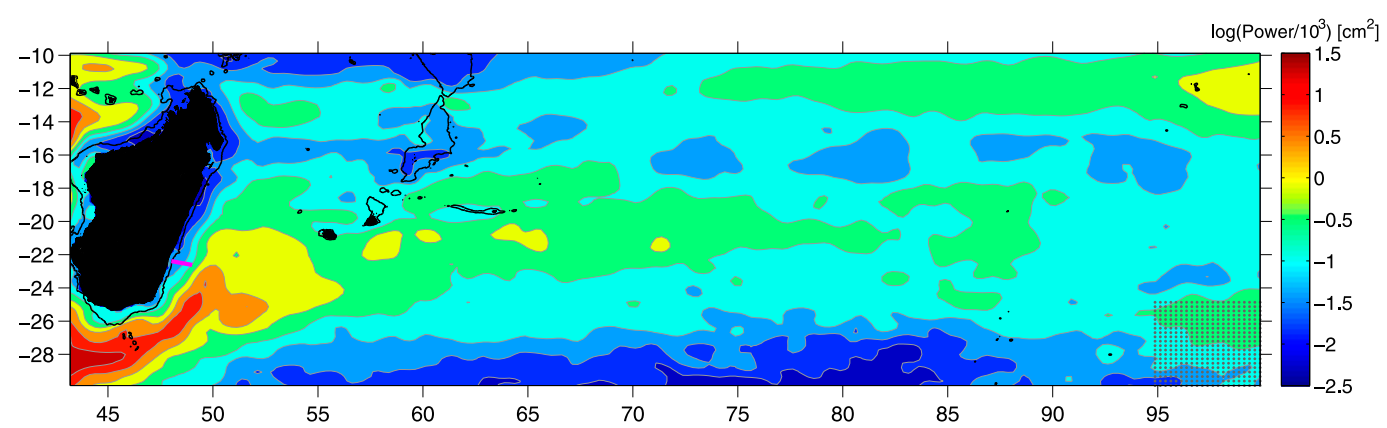

FIG. 13. Power density (plotted on logarithmic scale) averaged over the 45-85-day period (band shown in Fig. 7c). The values are estimated from the wavelet analysis applied to the normalized (by standard deviation) time series of SLA at every point of the AVISO grid. For the entire domain (all time series), the spectra show values over the $95 \%$ significance level at the nearly bimonthly period. The magenta line off eastern Madagascar indicates the position of the INATEX array, while black contours indicate the isobath of $1000 \mathrm{~m}$ plotted to highlight the location of the Mascarene Ridge at approximately $60^{\circ} \mathrm{E}$. The points in the lower-right corner illustrate the spatial resolution $\left(0.25^{\circ}\right)$ of the AVISO grid.

2011-13, when the transport dropped again. Taking the averages over each of these periods of years, poleward transports of 0.30 (1993-2001), 0.33 (2002-10), and $0.25 \mathrm{~Sv}(2011-13)$ are found.

\section{Discussion and conclusions}

Based on both $\sim 2.5 \mathrm{yr}$ of continuous in situ measurements, from a 5-moorings array deployed nominally at $23^{\circ} \mathrm{S}$ off eastern Madagascar and $\sim 21 \mathrm{yr}$ of satellite altimeter data, this paper provides a study of the East Madagascar Current (EMC) in terms of its observed velocities, estimated volume transport, and variability.

On average, the in situ observations reveal a poleward EMC between 60 and $100 \mathrm{~km}$ wide, from the surface to about $1000-\mathrm{m}$ depth. Its mean core is found about $20 \mathrm{~km}$ away from the coast, with velocities of $79( \pm 21) \mathrm{cm} \mathrm{s}^{-1}$. Events with velocities stronger than $150 \mathrm{~cm} \mathrm{~s}^{-1}$ were sampled during a few days, while the global peak reached up to $170 \mathrm{~cm} \mathrm{~s}^{-1}$.

The velocity time series (Fig. 3) show a well-organized western boundary current at surface levels. At intermediate levels $(\sim 1260 \mathrm{~m})$ and attached to the continental slope, a reversal of the flow indicates the presence of an equatorward undercurrent, the East Madagascar Undercurrent (EMUC; Ponsoni et al. 2015a). Figure 3 also shows the EMC crossing the transect more inclined toward the coast at the mooring EMC2 than at EMC4. A potential explanation for this is that the boundary currents tend to flow along the isobaths to conserve potential vorticity and the EMC2 mooring is placed over the continental slope, where the isobaths immediately upstream of the mooring array are also inclined toward the coast (see 200-, 500-, $1000-$, and $2000-\mathrm{m}$ isobaths, between $\sim 22^{\circ}$ and $28^{\circ} \mathrm{S}$, in Fig. 1b). This interaction with the bottom is reduced offshore, at EMC4, where the cross-shore gradient of depth is reduced and the local depth is about $3800 \mathrm{~m}$.

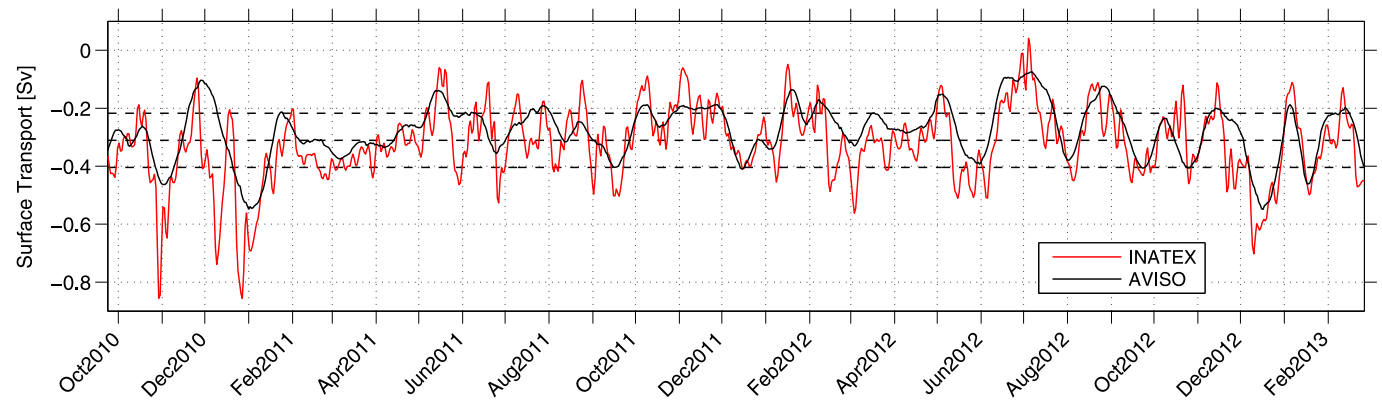

FIG. 14. Volume transport estimated for the surface layer (first $8 \mathrm{~m}$ of the water column) between moorings EMC2 and EMC5. The transport represented by the red line is based on in situ velocities from the INATEX moorings, while the transport represented by the black line is based on geostrophic velocities estimated from ADT. For every horizontal grid point, the velocity is assumed constant in the first $8 \mathrm{~m}$ of the water column. The black dashed lines indicate the mean and the standard deviation of the 21-yr altimeter-based volume transport. 

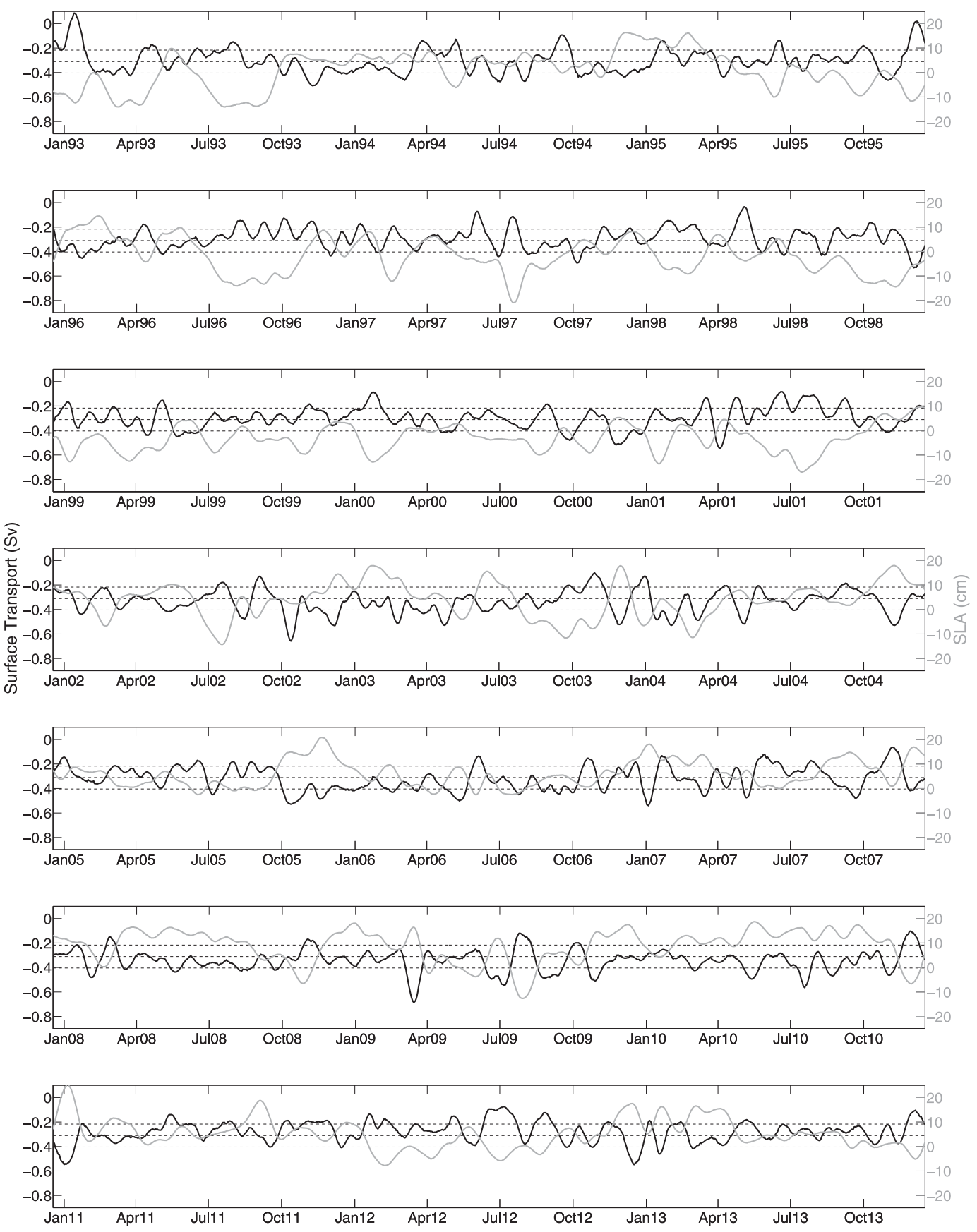

FIG. 15. Volume transport (left $y$ axis, black line) calculated within the surface layer (first $8 \mathrm{~m}$ of the water column) based on altimeter-derived geostrophic velocities. The black dashed lines represent the average and one standard deviation from the average. The gray line (right $y$ axis) represents the mean sea level anomaly calculated for the region highlighted by the black rectangle in Fig. 10.

The mean transport of the EMC, estimated with the in situ velocities, amounts to $18.3( \pm 8.4) \mathrm{Sv}$. This is in good agreement with the transport of $20.3( \pm 6.6) \mathrm{Sv}$ estimated by Schott et al. (1988), who analyzed 11 months of continuous observations from three vertical lines of moorings longitudinally deployed slightly north of our moorings. In the strongest event, measured from 12 to 20 January 2011, the EMC presented a transport over 50Sv. The deeper and oppositely directed EMUC has a mean volume transport much weaker than the overhead flow $(<1.4 \mathrm{~Sv}$; Ponsoni et al. 2015a). 

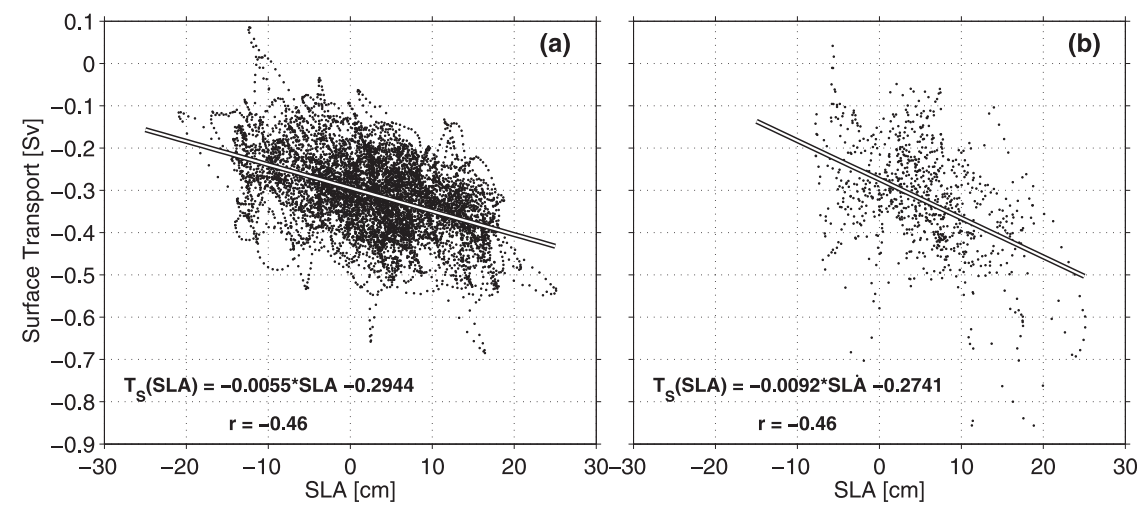

FIG. 16. Scatterplot of the surface volume transport, estimated from (a) altimeter and (b) in situ observations vs the mean sea level anomaly calculated for the region highlighted by the black rectangle in Fig. 10. The $\mathrm{T}_{\mathrm{S}}$ (SLA) values represent the first-order polynomial fit, while $r$ indicates the correlation coefficient between both parameters.

If indeed the entire volume transport of the EMC participates in building up the Agulhas Current (AC), the EMC contributes about $26.5 \%$ to the AC transport, which is estimated to be $77( \pm 5) \mathrm{Sv}$ at $32^{\circ} \mathrm{S}$ (Beal et al. 2015). Likewise, the flow from the Mozambique Channel would contribute about $22 \%$, since its mean poleward transport is $16.7( \pm 3.1) \mathrm{Sv}$ (Ridderinkhof et al. 2010). It is important to mention that a large part of the AC transport is due to the contribution of the AC's recirculation (Stramma and Lutjeharms 1997). Nevertheless, these percentages present crude estimates since the calculations are based on mean values.

The wavelet spectrum (Fig. 7) indicates a nearly bimonthly period (45-85 days) as the most prominent band of variability in the EMC transport, which explained $41 \%$ of the total variance. Schott et al. (1988) found similar variability of 40 to 55 days but explaining only $15 \%$ of the total variance. A potential explanation for this disparity is the fact that the results from Schott et al. (1988) are based on a shorter time series (11 months), and in this work we showed (section 4a) that the nearly bimonthly fluctuations can be interrupted over time, as, for instance, when a quasi-standing cyclonic eddy was observed in the vicinity of the INATEX moorings for a time span of about 3.5 months.

Altimeter data indicate that the bimonthly variability is induced by the arrival of westward-propagating sea level anomalies (SLA). In this paper, we treat these features as anticyclonic eddies (AE, positive SLA) and cyclonic eddies (CE, negative SLA), since most of the anomalies are nearly circular as might be expected for vortical eddies, rather than being elongated meridionally, which would characterize wave fronts (Quartly et al. 2005). However, we are aware of the ongoing discussion in the literature whether or not these entities are "Lagrangian coherent structures" that trap fluid and
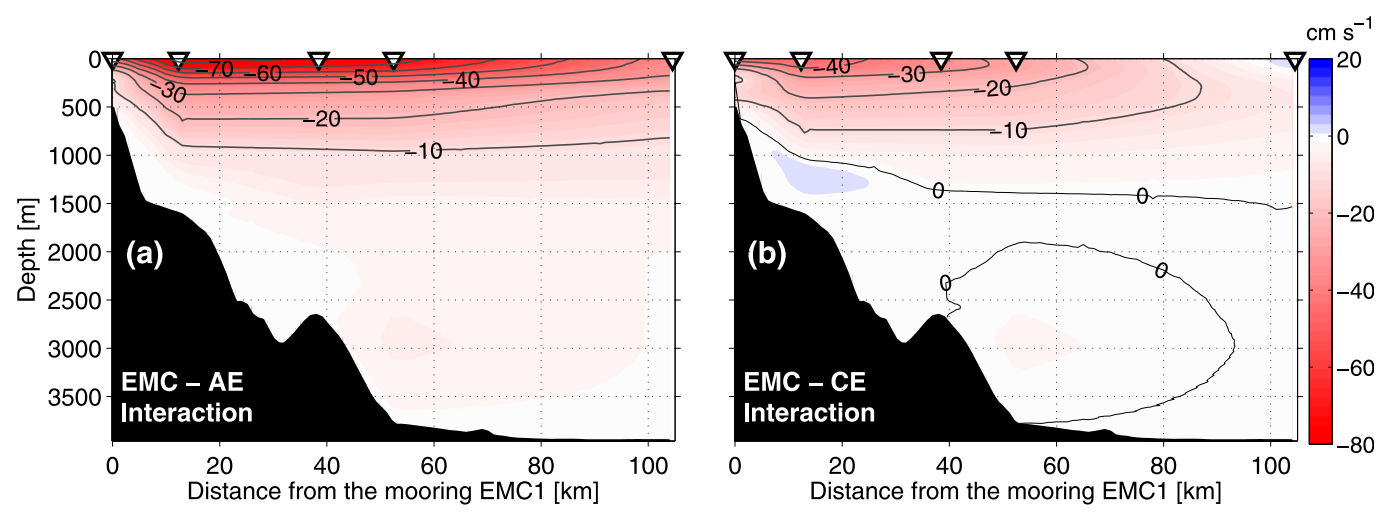

FIG. 17. Alongshore velocities averaged for all moments when an outstanding EMC-eddy interaction takes place between October 2010 and March 2013. (a) EMC-AE interactions, distinguished by the moments when the surface volume transport is less than one standard deviation away from the mean represented in Fig. 15. (b) EMC-CE interactions, distinguished by the moments when the surface volume transport is more than one standard deviation away from the mean represented in Fig. 15. 


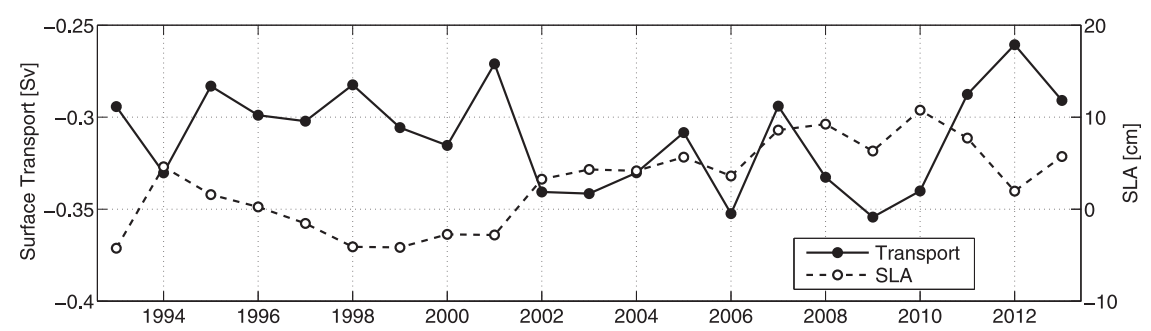

FIG. 18. Annual averages of altimeter-based volume transport (left $y$ axis) and mean sea level anomaly (right $y$ axis) calculated for the region highlighted by the black rectangle in Fig. 10 .

material (Haller 2002, 2005; Beron-Vera et al. 2008; Samelson 2013). Here, we follow other works (e.g., Faghmous et al. 2015) and treat these nearly circular SLAs as eddies, independent of their trapping ability.

Upon approach of the Madagascar coast, the eddies interact with the western boundary, and, depending on the rotation of the vortical structure, the current is intensified or attenuated. During EMC-AE interactions, the poleward flow at the shoremost side of the eddy adds to the current, while the opposite is observed when EMC-CE interactions take place.

The behavior of the eddies is intriguing once the interaction with the current is established. Some eddies propagate downstream, others remain quasi-steady interacting with the EMC for a long period (as the instance reported above) and some dissipate in the western boundary. Related to the last case, Zhai et al. (2010) showed that there is a significant sink of ocean eddy energy near western boundaries.

According to Shi and Nof (1994), three mechanisms influence the alongshore migration of the eddies when they reach the western boundary coast: (i) the image or mirror effect (Shi and Nof 1993; Kundu and Cohen 2008), when the collision of an eddy with the coast creates a mirror of the vortex with opposite signal and consequently the parent eddy migrates along the wall and is drifted forward by its own image; (ii) the rocket force, which occurs due to the fluid that leaks from the interior of the eddy and forms a thin jet advecting the eddy in the direction opposite to the leakage; and (iii) $\beta$-induced force, due to the differences in the Coriolis force in both hemispheres of the eddy. Azevedo et al. (2012) presented a detailed sketch of these forces influencing the migration of an eddy along a continental wall (their Fig. 3). The balance among these three forces determines the direction of the eddy migration along the wall. For instance, an AE (CE) in the Southern Hemisphere is forced poleward (equatorward) by mechanisms $i$ and ii and equatorward (poleward) by iii. Overall, the $\mathrm{AE}$ tends to drift poleward since mechanisms i and ii are stronger than iii (Shi and Nof 1994). In this context, for the case where CEs were observed standing offshore the
INATEX moorings, we can speculate that somehow at these moments the mechanisms $i$ and ii that would induce the equatorward propagation of the cyclonic structure were counterbalanced by the poleward EMC.

Some important questions still need to be better investigated, such as, how much does the EMC transport account for the buildup of the AC? Why do some of the CEs arriving near the coast maintain their position for longer than 3 months, while other vortical features disappear or propagate southward as soon as they interact with the EMC? Do the westward-propagating eddies that modulate the EMC variability ride on Rossby waves (e.g., Polito and Sato 2015)? These topics should be addressed in detail in future work.

Acknowledgments. We thank two anonymous reviewers for their constructive suggestions and criticism. The INATEX program was funded by Netherlands Organization for Scientific Research (NWO), section Earth and Life Sciences (ALW), through its ZKO Grant 839.08.431. We thank the crew and technicians of the FRS Algoa and all who participated in the INATEX cruises. J. Ullgren and W. de Ruijter are gratefully acknowledged for discussions and suggestions about the data processing and scientific contents, respectively. The altimeter products were produced by Ssalto/Duacs and distributed by AVISO with support from CNES. The first author is grateful to Coordenação de Aperfeiçoamento de Pessoal de Nível Superior (CAPES), Brazil, for the concession of a grant.

\section{REFERENCES}

Azevedo, J. L. L., D. Nof, and M. M. Mata, 2012: Eddy-train encounters with a continental boundary: A South Atlantic case study. J. Phys. Oceanogr., 42, 1548-1565, doi:10.1175/JPO-D-11-027.1.

Beal, L. M., 2009: A time series of Agulhas Undercurrent transport. J. Phys. Oceanogr., 39, 2436-2450, doi:10.1175/2009JPO4195.1. , and H. L. Bryden, 1997: Observations of an Agulhas Undercurrent. Deep-Sea Res. I, 44, 1715-1724, doi:10.1016/ S0967-0637(97)00033-2.

, and - 1999: The velocity and vorticity structure of the Agulhas Current at $32^{\circ}$ S. J. Geophys. Res., 104, 5151-5176, doi:10.1029/1998JC900056. 
- - and Coauthors, 2011: On the role of the Agulhas system in ocean circulation and climate. Nature, 472, 429-436, doi:10.1038/nature09983.

- S. Elipot, A. Houk, and G. M. Leber, 2015: Capturing the transport variability of a western boundary jet: Results from the Agulhas Current Time-Series Experiment (ACT). J. Phys. Oceanogr., 45, 1302-1324, doi:10.1175/JPO-D-14-0119.1.

Beron-Vera, F. J., M. J. Olascoaga, and G. J. Goni, 2008: Oceanic mesoscale eddies as revealed by Lagrangian coherent structures. Geophys. Res. Lett., 35, L12603, doi:10.1029/ 2008GL033957.

Carter, E. F., and A. R. Robinson, 1987: Analysis models for the estimation of oceanic fields. J. Atmos. Oceanic Technol., 4, 49-74, doi:10.1175/1520-0426(1987)004<0049:AMFTEO>2.0.CO;2.

Chapman, P., S. F. DiMarco, R. E. Davis, and A. C. Coward, 2003: Flow at intermediate depths around Madagascar based on ALACE float trajectories. Deep-Sea Res. II, 50, 1957-1986, doi:10.1016/S0967-0645(03)00040-7.

Chen, Z., L. Wu, B. Qiu, S. Sun, and F. Jia, 2014: Seasonal variation of the South Equatorial Current bifurcation off Madagascar. J. Phys. Oceanogr., 44, 618-631, doi:10.1175/JPO-D-13-0147.1.

da Silveira, I. C. A., L. Calado, B. M. Castro, M. Cirano, J. A. M. Lima, and A. S. Mascarenhas, 2004: On the baroclinic structure of the Brazil Current-intermediate western boundary current system at $22^{\circ}-23^{\circ} \mathrm{S}$. Geophys. Res. Lett., 31, L14308, doi:10.1029/2004GL020036.

de Ruijter, W. P. M., A. Biastoch, S. S. Drijfhout, J. R. E. Lutjeharms, R. P. Matano, T. Pichevin, P. J. van Leeuwen, and W. Weijer, 1999: Indian-Atlantic interocean exchange: Dynamics, estimation and impact. J. Geophys. Res., 104, 20 885-20 910, doi:10.1029/1998JC900099.

- H. Ridderinkhof, J. R. E. Lutjeharms, M. W. Schouten, and C. Veth, 2002: Observations of the flow in the Mozambique Channel. Geophys. Res. Lett., 29, doi:10.1029/2001GL013714. , H. M. van Aken, E. J. Beier, J. R. E. Lutjeharms, R. P. Matano, and M. W. Schouten, 2004: Eddies and dipoles around South Madagascar: Formation, pathways and large-scale impact. Deep-Sea Res. I, 51, 383-400, doi:10.1016/j.dsr.2003.10.011.

- H. Ridderinkhof, and M. W. Schouten, 2005: Variability of the southwest Indian Ocean. Philos. Trans. Roy. Soc. London, A363, 63-76, doi:10.1098/rsta.2004.1478.

DiMarco, S. F., P. Chapman, W. D. Nowlin Jr., P. Hacker, K. Donohue, M. Luther, G. C. Johnson, and J. Toole, 2002: Volume transport and property distributions of the Mozambique Channel. Deep-Sea Res. II, 49, 1481-1511, doi:10.1016/S0967-0645(01)00159-X.

Duncan, C. P., 1970: The Agulhas Current. Ph.D. thesis, University of Hawaii, 76 pp.

Faghmous, J. H., I. Frenger, Y. Yao, R. Warmka, A. Lindell, and V. Kumar, 2015: A daily global mesoscale ocean eddy dataset from satellite altimetry. Sci. Data, 2, 150028, doi:10.1038/sdata.2015.28.

Fomin, L. M., 1964: The Dynamic Method in Oceanography. Elsevier, $211 \mathrm{pp}$.

Gordon, A. L., R. Weiss, W. M. Smethie Jr., and M. J. Warner, 1992: Thermocline and intermediate water communication between the South Atlantic and Indian Oceans. J. Geophys. Res., 97, 7223-7240, doi:10.1029/92JC00485.

Gründlingh, M. L., 1993: On the winter flow in the southern Mozambique Channel. Deep-Sea Res. I, 40, 409-418, doi:10.1016/ 0967-0637(93)90011-Q.

Haller, G., 2002: Lagrangian coherent structures from approximate velocity data. Phys. Fluids, 14, 1851-1861, doi:10.1063/ 1.1477449 .
2005: An objective definition of a vortex. J. Fluid Mech., 525, 1-26, doi:10.1017/S0022112004002526.

Harris, T. F. W., 1972: Sources of the Agulhas Current in the spring of 1964. Deep-Sea Res. Oceanogr. Abstr., 19, 633-650, doi:10.1016/0011-7471(72)90091-5.

Kundu, P. K., and I. M. Cohen, 2008: Fluid Mechanics. Academic Press, 878 pp.

Lutjeharms, J. R. E., 1988: Remote sensing corroboration of retroflection of the East Madagascar Current. Deep-Sea Res., 35A, 2045-2050, doi:10.1016/0198-0149(88)90124-0. , 2006: The Agulhas Current. Springer, 329 pp.

— N. D. Bang, and C. P. Duncan, 1981: Characteristics of the currents east and south of Madagascar. Deep-Sea Res., 28A, 879-899, doi:10.1016/0198-0149(81)90008-X.

Matano, R. P., E. J. Beier, P. T. Strub, and R. Tokmakian, 2002: Large-scale forcing of the Agulhas variability: The seasonal cycle. J. Phys. Oceanogr., 32, 1228-1241, doi:10.1175/ 1520-0485(2002)032<1228:LSFOTA $>2.0 . C O ; 2$.

Nauw, J. J., H. M. van Aken, A. Webb, J. R. E. Lutjeharms, and W. P. M. de Ruijter, 2008: Observations of the southern East Madagascar Current and undercurrent and countercurrent system. J. Geophys. Res., 113, C08006, doi:10.1029/2007JC004639.

New, A. L., S. G. Anderson, D. A. Smeed, and K. L. Stansfield, 2007: On the circulation of water masses across the Mascarene Plateau in the south Indian Ocean. Deep-Sea Res. I, 54, 42-74, doi:10.1016/j.dsr.2006.08.016.

Olson, D. B., and R. H. Evans, 1986: Rings of the Agulhas Current. Deep-Sea Res., 33A, 27-42, doi:10.1016/0198-0149(86)90106-8.

Palastanga, V., P. J. van Leeuwen, and W. P. M. de Ruijter, 2006: A link between low-frequency mesoscale eddy variability around Madagascar and the large-scale Indian Ocean variability. J. Geophys. Res., 111, C09029, doi:10.1029/2005JC003081.

,,-- M. W. Schouten, and W. P. M. de Ruijter, 2007: Flow structure and variability in the subtropical Indian Ocean: Instability of the South Indian Ocean Countercurrent. J. Geophys. Res., 112, C01001, doi:10.1029/2005JC003395.

Polito, P. S., and O. Sato, 2015: Do eddies ride on Rossby waves? J. Geophys. Res., 120, 5417-5435, doi:10.1002/2015JC010737.

Ponsoni, L., B. Aguiar-González, L. R. M. Maas, H. M. van Aken, and H. Ridderinkhof, 2015a: Long-term observations of the East Madagascar Undercurrent. Deep-Sea Res. I, 100, 64-78, doi:10.1016/j.dsr.2015.02.004.

- - - J. J. Nauw, H. Ridderinkhof, and L. R. M. Maas, 2015b: First observational evidence of a North Madagascar Undercurrent. Dyn. Atmos. Oceans, 72, 12-20, doi:10.1016/ j.dynatmoce.2015.08.002.

Quartly, G. D., J. J. H. Buck, and M. A. Srokosz, 2005: Eddy variability east of Madagascar. Philos. Trans. Roy. Soc. London, A363, 77-79, doi:10.1098/rsta.2004.1479.

_ $, \ldots, \ldots$, and A. C. Coward, 2006: Eddies around Madagascar-The retroflection re-considered. J. Mar. Syst., 63, 115-129, doi:10.1016/j.jmarsys.2006.06.001.

Ridderinkhof, H., and W. P. M. de Ruijter, 2003: Moored current observations in the Mozambique Channel. Deep-Sea Res. II, 50, 1933-1955, doi:10.1016/S0967-0645(03)00041-9.

_, P. M. van der Werf, J. E. Ullgren, H. M. van Aken, P. J. van Leeuwen, and W. P. M. de Ruijter, 2010: Seasonal and interannual variability in the Mozambique Channel from moored current observations. J. Geophys. Res., 115, C06010, doi:10.1029/2009JC005619.

Ridderinkhof, W., D. Le Bars, A. S. von der Heydt, and W. P. M. de Ruijter, 2013: Dipoles of the South East Madagascar Current. Geophys. Res. Lett., 40, 558-562, doi:10.1002/grl.50157. 
Rio, M.-H., S. Mulet, and N. Picot, 2014: Beyond GOCE for the ocean circulation estimate: Synergetic use of altimetry, gravimetry, and in situ data provides new insight into geostrophic and Ekman currents. Geophys. Res. Lett., 41, 8918-8925, doi:10.1002/2014GL061773.

Samelson, R. M., 2013: Lagrangian motion, coherent structures, and lines of persistent material strain. Annu. Rev. Mar. Sci., 5, 137-163, doi:10.1146/annurev-marine-120710-100819.

Schott, F., M. Fieux, J. Kindle, J. Swallow, and R. Zantopp, 1988: The boundary currents east and north of Madagascar: 2. Direct measurements and model comparisons. J. Geophys. Res. 93, 4963-4974, doi:10.1029/JC093iC05p04963.

_ , S.-P. Xie, and J. P. McCreary Jr., 2009: Indian Ocean circulation and climate variability. Rev. Geophys., 47, RG1002, doi:10.1029/2007RG000245.

Schouten, M. W., W. P. M. de Ruijter, and P. J. van Leeuwen, 2002a: Upstream control of Agulhas ring shedding. J. Geophys. Res., 107, doi:10.1029/2001JC000804.

,,--- , and H. A. Dijkstra, 2002b: An oceanic teleconnection between the equatorial and southern Indian Ocean. Geophys. Res. Lett., 29, doi:10.1029/2001GL014542.

Shi, C., and D. Nof, 1993: The splitting of eddies along boundaries. J. Mar. Res., 51, 771-795, doi:10.1357/0022240933223927. , and - 1994: The destruction of lenses and generation of wodons. J. Phys. Oceanogr., 24, 1120-1136, doi:10.1175/ 1520-0485(1994)024<1120:TDOLAG > 2.0.CO;2.

Siedler, G., M. Rouault, and J. R. E. Lutjeharms, 2006: Structure and origin of the subtropical South Indian Ocean Countercurrent. Geophys. Res. Lett., 33, L24609, doi:10.1029/2006GL027399.
Stramma, L., and J. R. E. Lutjeharms, 1997: The flow field of the subtropical gyre of the South Indian Ocean. J. Geophys. Res., 102, 5513-5530, doi:10.1029/96JC03455.

Swallow, J., M. Fieux, and F. Schott, 1988: The boundary currents east and north of Madagascar: 1. Geostrophic currents and transports. J. Geophys. Res., 93, 4951-4962, doi:10.1029/ JC093iC05p04951.

Torrence, C., and G. P. Compo, 1998: A practical guide to wavelet analysis. Bull. Amer. Meteor. Soc., 79, 61-78, doi:10.1175/ 1520-0477(1998)079<0061:APGTWA >2.0.CO;2.

Ullgren, J. E., H. M. van Aken, H. Ridderinkhof, and W. P. M. de Ruijter, 2012: The hydrography of the Mozambique Channel from six years of continuous temperature, salinity, and velocity observations. Deep-Sea Res. I, 69, 36-50, doi:10.1016/ j.dsr.2012.07.003

van Aken, H. M., H. Ridderinkhof, and W. P. M. de Ruijter, 2004: North Atlantic deep water in the south-western Indian Ocean. Deep-Sea Res. I, 51, 755-776, doi:10.1016/ j.dsr.2004.01.008.

Warren, B. A., T. Whitworth III, and J. H. LaCasce, 2002: Forced resonant undulation in the deep Mascarene basin. Deep-Sea Res. II, 49, 1513-1526, doi:10.1016/S0967-0645(01)00151-5.

Weijer, W., 2008: Normal modes of the Mascarene basin. Deep-Sea Res. I, 55, 128-136, doi:10.1016/j.dsr.2007.10.005.

Wyrtki, K., 1971: Oceanographic Atlas of the International Indian Ocean Expedition. National Science Foundation, 531 pp.

Zhai, X., H. L. Johnson, and D. P. Marshall, 2010: Significant sink of ocean-eddy energy near western boundaries. Nat. Geosci., 3, 608-621, doi:10.1038/ngeo943. 